Check for updates

Cite this: RSC Adv., 2019, 9, 19662

Received 14th April 2019

Accepted 3rd June 2019

DOI: $10.1039 / c 9 r a 02825 k$

rsc.li/rsc-advances

\section{Tungsten anchored onto functionalized SBA-15: an efficient catalyst for diastereoselective synthesis of 2-azapyrrolizidine alkaloid scaffolds $\dagger$}

\begin{abstract}
Javad Safaei-Ghomi (D) * and Atefeh Bakhtiari
We used a novel hybrid catalyst in chemo-, regio-, and diastereoselective multi-component reactions (MCR) for the synthesis of the 2-aza analogue of pyrrolizidine and spirooxindole-2-azapyrrolizidine derivatives. The nanocatalyst, W(Iv)/NNBIA-SBA-15 [where NNBIA $=N, N^{\prime}$-(ethane-1,2-diyl)bis(2aminobenzamide)] was synthesized by covalent grafting on chloro-functionalized SBA-15. The synthesis process was followed by the anchoring of $\mathrm{WCl}_{6}$ to catch the desired catalyst. The quality of the catalyst was assessed using different analytical techniques such as X-ray diffraction spectroscopy (XRD), Fouriertransform infrared spectroscopy (FT-IR), $\mathrm{N}_{2}$ adsorption analysis, transmission electron microscopy (TEM), field emission scanning electron microscopy (FESEM), energy-dispersive X-ray spectroscopy (EDX), ammonia Temperature Programmed Desorption (TPD), X-Ray photoelectron spectroscopy (XPS) and thermogravimetric, differential thermal analysis (TGA-DTA). The catalyst, W(IV)/NNBIA-SBA-15, with high catalytic performance is a good candidate for the diastereoselective synthesis of 2-azapyrrolizidine alkaloid scaffolds. The catalyst could be recovered for reuse without noticeable loss of activity.
\end{abstract}

\section{Introduction}

Chemical researchers are focused on the synthesis of functionalized nitrogen and oxygen-containing organic compounds that have potential medicinal and biological activities., ${ }^{1,2}$ Diversity-oriented synthesis (DOS) is one of the strategies used to provide synthetic methods for the efficient combination of regiochemically and functionally diverse simple molecules. ${ }^{3-5}$ DOS is especially useful for those structures based on natural products or drug-like molecules. ${ }^{6,7}$ The aim of DOS is to achieve simultaneous, deliberate, and impressive syntheses of structurally diverse compounds such as drug molecules or natural products..$^{3-5,8}$ MCRs $^{9}$ can be placed in the class of DOS chemistry due to green characteristics, straightforward reaction designs, high degrees of atom economy, lower costs and environmentally friendliness. ${ }^{10}$ The use of water in chemical reactions has many advantages in the field of green chemistry, such as modifying the reactivity and selectivity of the reaction. ${ }^{11}$

Spirocyclic structures that contain one $\mathrm{sp}^{3}$ carbon atom common to two rings have many biological properties. They have attracted the considerable attention of organic chemists because of being in natural ingredients. ${ }^{12}$

Department of Organic Chemistry, Faculty of Chemistry, University of Kashan, P. O. Box 87317-51167, Kashan, I. R. Iran. E-mail: safaei@kashanu.ac.ir; Fax: +98 31 55552935; Tel: +983155912385

$\dagger$ Electronic supplementary information (ESI) available. See DOI: $10.1039 / \mathrm{c} 9 \mathrm{ra} 02825 \mathrm{k}$
One of the most important classes of biological compounds is hydantoins..$^{13-15}$ The presence of three disparate nucleophilic centers in hydantoin provides the ability to synthesize many biologically active molecules from several alternative cyclization pathways. ${ }^{16}$ Pyrrolizidine alkaloids consisting of two fused fivemember carbon rings with a nitrogen atom at one bridgehead belong to the aza-heterocyclic family. ${ }^{17}$ They are commonly used in chemical biology and medicinal chemistry due to their medicinal properties. ${ }^{18,19}$ The presence of a nitrogen-substituted carbon in the stereogenic center of pyrrolizidine alkaloids increases their biological properties. Some of their derivatives such as retronecine, ${ }^{20}$ heliotridine, ${ }^{21}$ and platynecine ${ }^{22}$ show anti-tumoural, anti-microbial, and anti-viral effects. In previous reports, conventional organic catalysts such as $\mathrm{NEt}_{3}$ (ref. 23) and piperidine $\mathrm{e}^{16,24}$ were employed for synthesizing 2-azapyrrolizidine alkaloid scaffolds.

Tungsten is a transition metal of Group VIb of the periodic table of elements, and it has attracted a great deal of attention due to its extraordinary properties. ${ }^{25}$ The use of tungsten in new applications has made it useful as an essential commodity in recent years. ${ }^{26}$ Tungsten based catalysts with unique functional properties have been widely used for various applications, such as the selective oxidation of unsaturated compounds, ${ }^{27}$ metathesis and isomerization of alkenes ${ }^{28}$ and the dehydrogenation of alcohols.$^{29}$ They are most useful for addition reactions to olefinic double bonds. ${ }^{30}$ Recently, researchers have attempted to insert tungsten into siliceous mesoporous molecular sieves (e.g., silica, M41S, and SBA-n $)^{31-33}$ by various methods such as grafting, ${ }^{34}$ cogelation,,$^{35}$ impregnation $^{36}$ or insertion. ${ }^{37}$ The diverse 
compositions of incorporated tungsten into siliceous mesoporous materials have resulted in improved catalytic activities.

Considerable attention has been paid to designing heterogeneous catalysts, due to their advantages such as easy separation, easy recovery, and high reusability. The surface support has an influential effect on the behavior of heterogeneous catalysts. Several solid supports have been introduced such as polymer resins, silica, alumina, silica-coated magnetic particles, and mesoporous molecular sieves. The fully ordered structure of mesoporous silica leads to the generation of a framework with regular porosity, so ligands could be immobilized well on it. Because of the advantages of mesoporous silica, it could be vastly employed in separation, catalysis, gas storage, drug delivery, and biomolecule applications. Since the development of ordered mesoporous silicas, ${ }^{38,39}$ SBA-15 materials developed by Zhao and Stucky ${ }^{\mathbf{4 0 , 4 1}}$ serve in many fields due to their interesting textural properties such as their appreciable thermal and hydrothermal stabilities, large pore volumes, uniform-sized pores (in the range $4-30 \mathrm{~nm}$ ) and high specific surface areas (above $1000 \mathrm{~m}^{2} \mathrm{~g}^{-1}$ ). ${ }^{42-48}$ The creation of organic-inorganic hybrid catalysts is the best methodology to overcome a lack of functionality by using a variety of organic functional groups. ${ }^{49-51}$ The unique abilities of organic-inorganic hybrid materials make these systems highly attractive candidates for a range of applications including recyclable catalysts, drug delivery, biotechnology, biomedicine etc. ${ }^{52-54}$ There are a number of methods for the synthesis of hybrids catalyst. Among them, stable attachment and less leaching ${ }^{55}$ are observed post-synthetically. The available ligand precursors can be used for multifunctional integration of SBA-15.

We are interested in the development of our research to prepare more effective catalysts to synthesize a 2-aza analogue

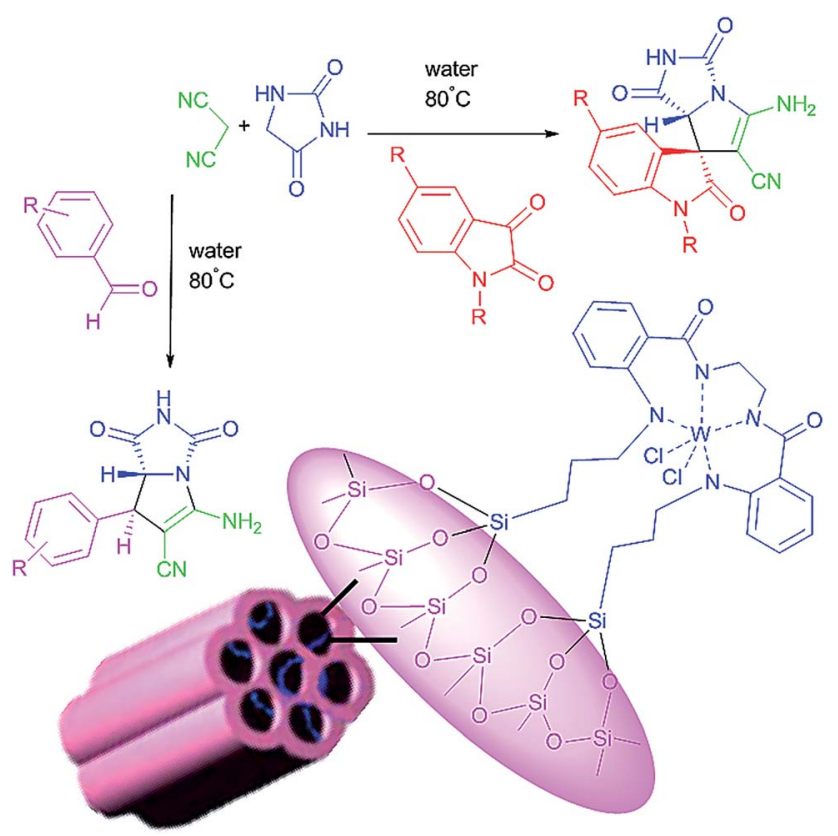

Scheme 1 Synthesis of the 2-aza analogue of pyrrolizidine and spirooxindole-2-azapyrrolizidine derivatives. of pyrrolizidine and spirooxindole-2-azapyrrolizidine derivatives. The nanocatalyst, W(Iv)/NNBIA-SBA-15, was prepared by applying simple and cost-effective materials and also it was characterized as a new inorganic-organic hybrid catalyst. The one-pot reactions of aldehyde or isatin $(1 \mathrm{mmol})$, malononitrile ( $1 \mathrm{mmol})$, and hydantoin (1 mmol) were catalyzed by $\mathrm{W}(\mathrm{Iv}) /$ NNBIA-SBA-15 in water (Scheme 1).

\section{Results and discussion}

\subsection{Structural analysis of $W(\mathrm{Iv}) /$ NNBIA-SBA-15}

A small angle X-ray diffraction method was used to monitor the effect of incorporation of the ligand, NNBIA, and the metal on the framework of SBA-15 (Fig. 1). The patterns for both of SBA15 and $\mathrm{W}(\mathrm{Iv}) / \mathrm{NNBIA}-\mathrm{SBA}-15$ show an intense diffraction peak (100) which references to the mesostructure with a remarkable degree of long-range ordering. The observed intensities of the two secondary peaks corresponding to (110) and (200) reflections are weak and they are attributed to the 2D-hexagonal planes of the mesoporous structure. ${ }^{56,57}$ The XRD pattern of W(Iv)/NNBIA-SBA-15 indicates a striking effect by loading of the ligand and the metal. The width and intensity of the diffraction peak (100) become broader and weaker respectively, and also it shifts to lower $2 \theta$ values than the XRD pattern of pure SBA-15. Partial blockage of the available pores of the anchored catalyst decreased the long-range order of SBA- $15 .{ }^{58}$ It can be inferred from the above results that the framework of SBA-15 remains perfect after incorporation of W(IV)-NNBIA.

The surface and structure properties of pure SBA-15 and W(Iv)/NNBIA-SBA-15 were evaluated by $\mathrm{N}_{2}$ adsorption-desorption isotherms analysis and $\mathrm{BJH}$ pore size distributions (Fig. 2). Both of them show a type IV isotherm with an $\mathrm{H} 1$ hysteresis loop which is in agreement with the typical mesostructure. The steep adsorption step at 0.4 to $0.8 P / P_{\mathrm{o}}$ corresponds to the capillary condensation of nitrogen in uniform pores. The

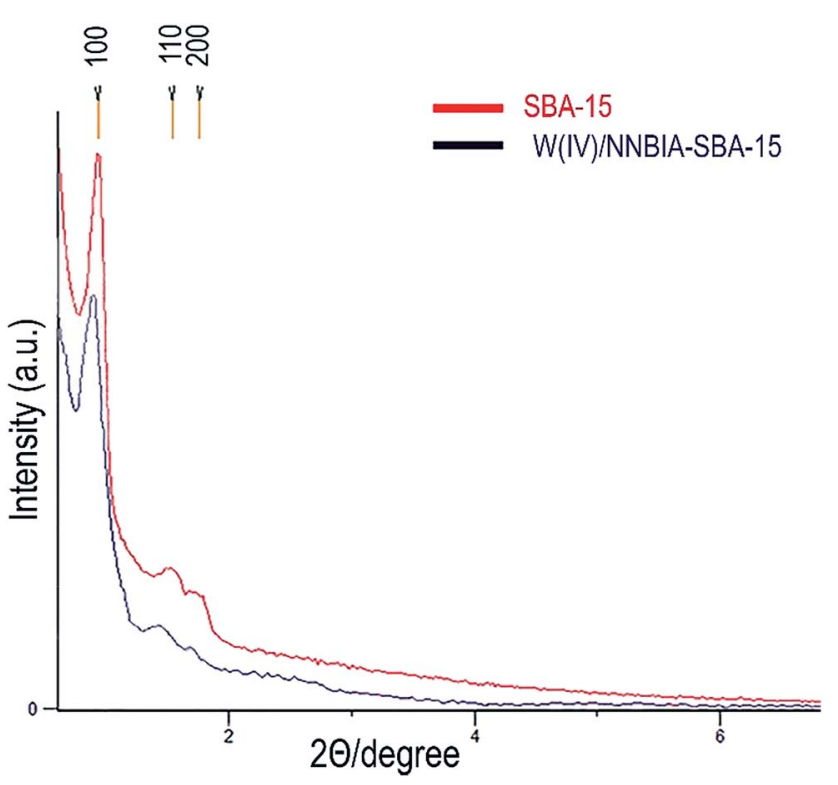

Fig. 1 The XRD patterns of SBA-15 and W(Iv)/NNBIA-SBA-15. 

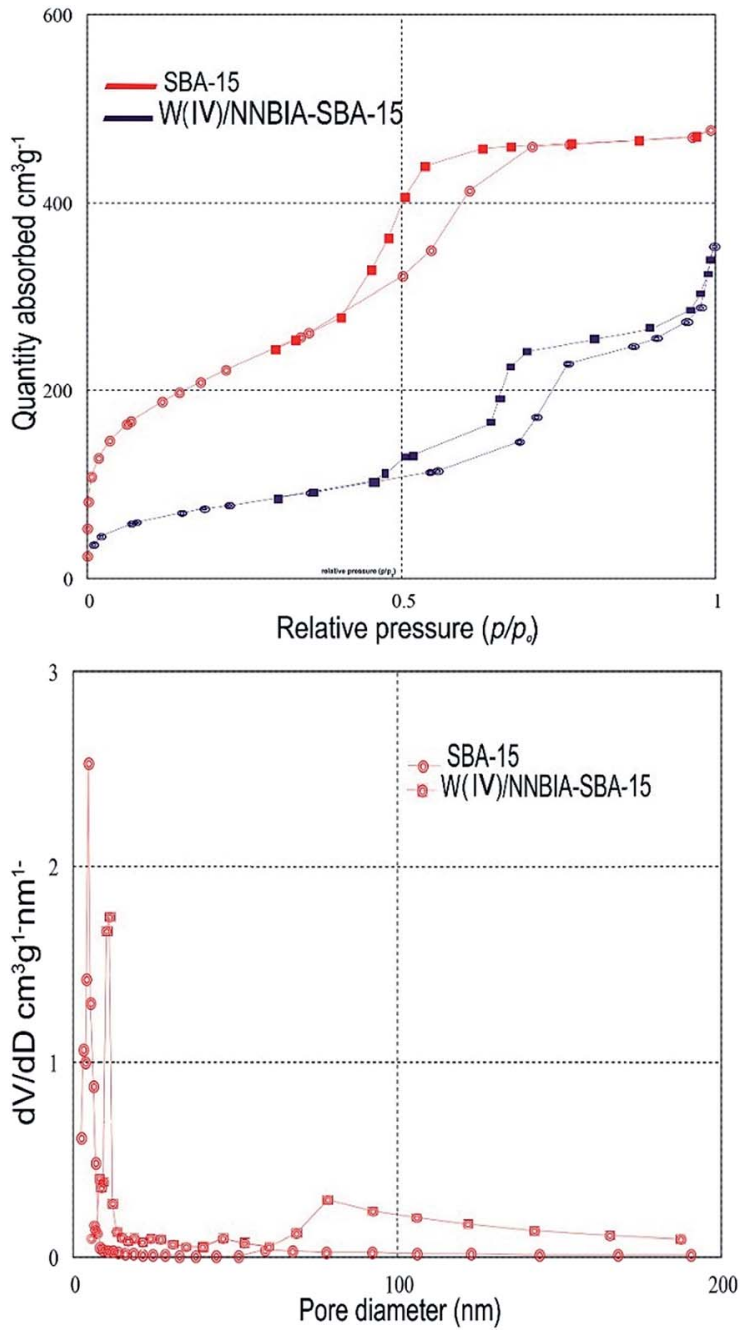

Fig. $2 \mathrm{~N}_{2}$ adsorption-desorption isotherms and $\mathrm{BJH}$ pore size distributions of SBA-15, and W(Iv)/NNBIA-SBA-15.

sharpness of the pore-filling step in the adsorption and desorption curves is related to the uniformity of the mesopore size distribution. Due to pore blocking effect, the functionalization of SBA-15 not only shifts the inflection to a lower $P / P_{\mathrm{o}}$ range but also diminishes the sharpness of it. ${ }^{43}$ The reduction in sharpness of the functionalized SBA-15 is due to less uniformity in the mesopore size distribution. The above results clearly indicate that the ordered mesoporous structure of SBA15 with a narrow pore size distributions remains well after immobilizing $\mathrm{W}(\mathrm{Iv}) /$ NNBIA. The BET surface area $\left(758 \mathrm{~m}^{2} \mathrm{~g}^{-1}\right)$, the average pore diameter $(9.4 \mathrm{~nm})$ and the total pore volume $\left(0.737 \mathrm{~cm}^{3} \mathrm{~g}^{-1}\right)$ of SBA-15 were recorded (Table 1$)$. The textural parameters of W(Iv)/NNBIA-SBA-15 are changed by the cooperation of the ligand and the metal. The data for the surface area, average pore width, and total pore volume for W(Iv)/NNBIASBA-15 are presented in Table 1 . The results show that $\mathrm{W}(\mathrm{Iv})$ is placed mainly inside the channels of the modified SBA-15 materials.

The incorporation efficiency and contents of the ligand and metal in the mesoporous SBA- 15 were analysed using an EDS
Table 1 Structural and textural parameters of SBA-15, and W(IV)/ NNBIA-SBA-15

\begin{tabular}{llll}
\hline Sample & $S_{\mathrm{BET}}{ }^{a}\left[\mathrm{~cm}^{2} \mathrm{~g}^{-1}\right]$ & $D_{\mathrm{P}}{ }^{b}[\mathrm{~nm}]$ & $V_{\mathrm{P}}{ }^{c}\left[\mathrm{~cm}^{3} \mathrm{~g}^{-1}\right]$ \\
\hline SBA-15 & 758.68 & 9.40 & 0.737 \\
$\mathrm{~W}(\mathrm{Iv}) /$ NNBIA-SBA-15 & 182.29 & 8.06 & 0.392 \\
${ }^{a} S_{\mathrm{BET}}=$ surface area. ${ }^{b} D_{\mathrm{p}}=$ average pore width. ${ }^{c} V_{\mathrm{p}}=$ total pore \\
volume.
\end{tabular}

spectrum (Fig. 3). The amount of carbon, nitrogen, oxygen, silicon, chlorine and tungsten in W(Iv)/NNBIA-SBA-15 were calculated to be $30.63,15.06,30.44,9.89,8.39,5.59$ (wt\%), respectively. The EDS mapping analysis suggested a highly uniform dispersion of the ligand, NNBIA and tungsten on SBA15.

The FESEM images of the SBA-15 and W(Iv)/NNBIA-SBA-15 are shown in Fig. 4a and b. The FESEM images show that both of them have good structural integrity and morphology. The surface morphology was not changed by functionalization. The evaluation of the used catalyst structure by FESEM evidences that the morphology of the catalyst remained unchanged after the 5th cycle (Fig. 4c). This is the feasible reason for the extreme stability of the catalyst. The presence of a 2D hexagonal network was confirmed by the TEM image of a W(Iv)/NNBIA-SBA-15 sample (Fig. 4d). The TEM image shows highly dispersed W(Iv)/NNBIA both inside and outside the channels of SBA-15.

FT-IR spectroscopy is an effective technique to confirm and identify the structure of a catalyst. Fig. 5 shows the FT-IR spectra at all stages of the process of creating the catalyst. The peaks of the absorption bands associated with the formation of a condensed silica network appear around 1077, 801, and $455 \mathrm{~cm}^{-1}$. The peak at $1077 \mathrm{~cm}^{-1}$ can be attributed to the asymmetric stretching vibration peak of $\mathrm{Si}-\mathrm{O}-\mathrm{Si}$ groups. The

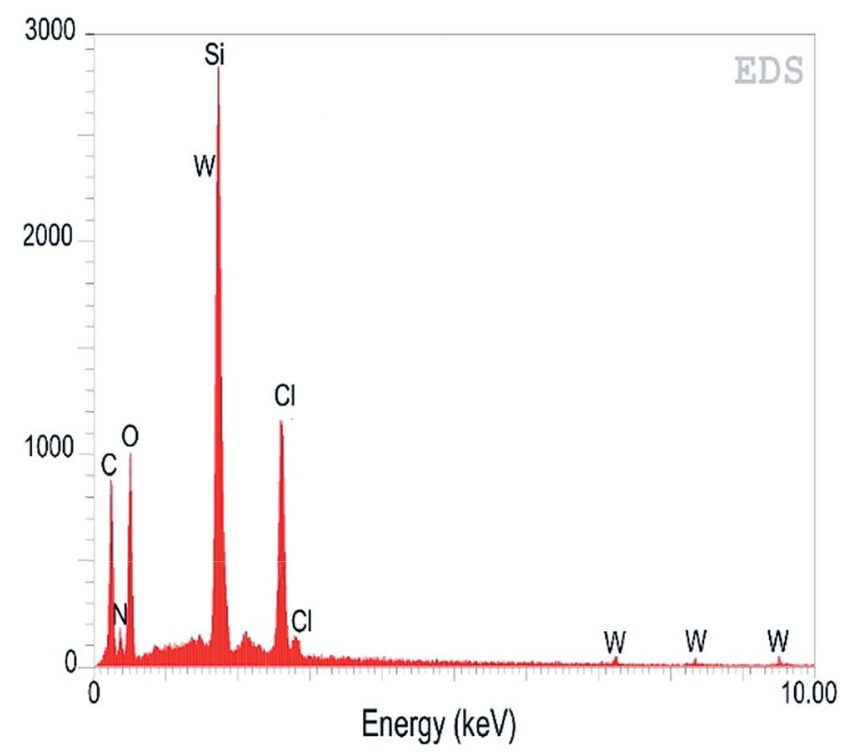

Fig. 3 EDS spectrum of W(IV)/NNBIA-SBA-15. 

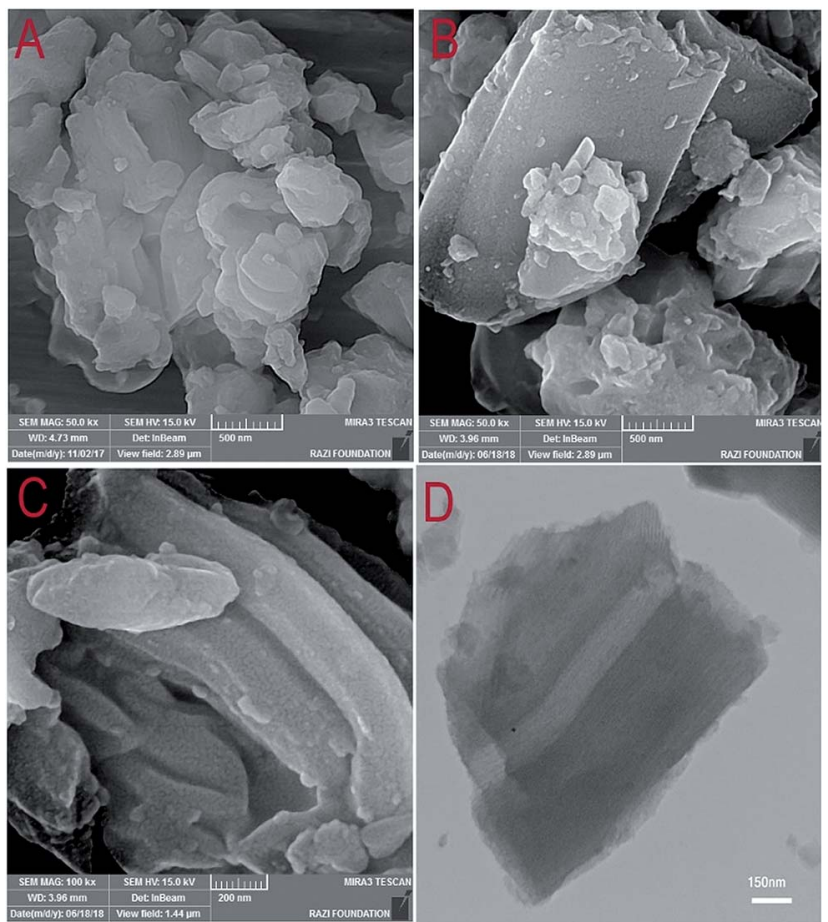

Fig. 4 FESEM images of (A) SBA-15, (B) W(IV)/NNBIA-SBA-15 and (C) the used W(IV)/NNBIA-SBA-15 and (D) A TEM image of W(IV)/NNBIASBA-15.

peaks at 3439 and $1632 \mathrm{~cm}^{-1}$ are due to the stretching and bending vibrations of the surface hydroxyl groups, respectively. ${ }^{48}$ The spectrum of chloro-functionalized SBA-15 shows a peak at $3114 \mathrm{~cm}^{-1}$ related to a C-H stretching vibration within the propyl group, and the peak at $709 \mathrm{~cm}^{-1}$ corresponds to the $\mathrm{C}-\mathrm{Cl}$ bonds. The FT-IR spectrum of the ligand, NNBIA, shows three strong absorption peaks due to the carbonyl groups and aromatic rings at 1548,1580 and $1629 \mathrm{~cm}^{-1}$. Three other peaks at 3285,3368 and $3474 \mathrm{~cm}^{-1}$ could be assigned to the $\mathrm{N}-\mathrm{H}$ bonds of the ligand. The absorption peaks of the carbonyl groups are shifted toward low frequencies with the immobilization of the ligand, NNBIA, over the Cl-SBA-15. Due to ligand binding, the peak of the $\mathrm{N}-\mathrm{H}$ bond was observed at $3319 \mathrm{~cm}^{-1}$ and the $\mathrm{C}-\mathrm{Cl}$ stretch disappeared. Coordination of $\mathrm{WCl}_{6}$ to NNBIA-SBA-15 led to the disappearance of a sharp absorption peak at $3319 \mathrm{~cm}^{-1}$ that could be attributed to the removal of the $\mathrm{N}-\mathrm{H}$ bonds. A wide peak at $3442 \mathrm{~cm}^{-1}$ could be attributed to some unreacted hydroxyl groups remaining on the surface of SBA-15. The combination of the organic ligand with the $\mathrm{W}$ is confirmed by these results. The reused catalyst after five runs had no obvious changes in structure, based on the results of the FT-IR spectrum when compared with the spectrum of the fresh catalyst.

The thermal behaviors of SBA- 15 and W(Iv)/NNBIA-SBA-15 from $30{ }^{\circ} \mathrm{C}$ to $800{ }^{\circ} \mathrm{C}$ are represented in Fig. 6. The TGA profile of the silica support exhibits two steps of weight loss. The first weight loss $(\sim 9 \%)$ is in the region from $\sim 150{ }^{\circ} \mathrm{C}$ to $250{ }^{\circ} \mathrm{C}$ and corresponds to a sharp visible exothermic peak in the DTA analysis in the same temperature region. This is

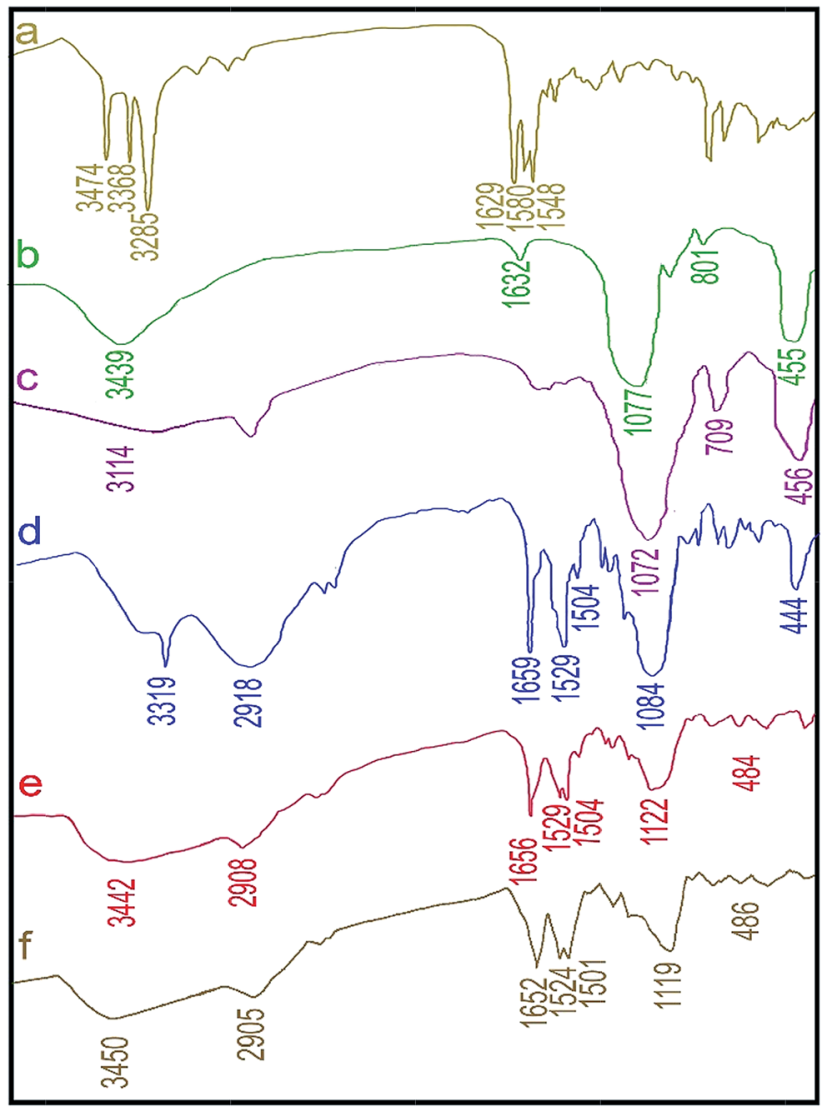

Wavenumber $\left(\mathrm{cm}^{-1}\right)$

Fig. 5 FT-IR spectra of (a) the ligand, NNBIA, (b) calcined SBA-15, (c) chlorofunctionalized SBA-15, (d) NNBIA-SBA-15, (e) fresh W(Iv)/ NNBIA-SBA-15 and (f) used W(IV)/NNBIA-SBA-15

related to the loss of physically bound water and the break-up of a hydrogen bonded network. The second region is from $\sim 200{ }^{\circ} \mathrm{C}$ to $800{ }^{\circ} \mathrm{C}$ and is associated to the dihydroxylation of $\mathrm{OH}$ groups. It can be evidently supported by one strong exothermic peak in the same temperature range in the DTA analysis. The TGA profile of $\mathrm{W}(\mathrm{Iv}) / \mathrm{NNBIA}-\mathrm{SBA}-15$ shows a weight loss of $36 \%$ in the temperature range of $350-600{ }^{\circ} \mathrm{C}$, which is accompanied by a broad exothermic peak between $370{ }^{\circ} \mathrm{C}$ and $750{ }^{\circ} \mathrm{C}$ in the DTA curve. This is associated with ligand desorption or decomposition. Based on these results, the amount of active catalyst present on the heterogeneous SBA support is $1.5 \mathrm{mmol}$. The decomposition of the W(rv)/NNBIA complex is done at a high temperature, and that demonstrates the high thermal stability of the complex. Consequently, the results reported thus far indicate that $\mathrm{W}(\mathrm{Iv}) / \mathrm{NNBIA}$ is formed and principally located, inside the SBA-15 pore channels.

The $\mathrm{NH}_{3}$-TPD profile of $\mathrm{W}(\mathrm{Iv}) / \mathrm{NNBIA-SBA-15}$ is shown in Fig. 7. The acid sites are distributed in two temperature regions. The second peak at about $450{ }^{\circ} \mathrm{C}$ is sharper and wider than the first one at about $250{ }^{\circ} \mathrm{C}$. They could be attributed to weak acid sites and medium-strong acid sites, respectively. The desorption peak at the low temperature of $250{ }^{\circ} \mathrm{C}$ was observed due to 

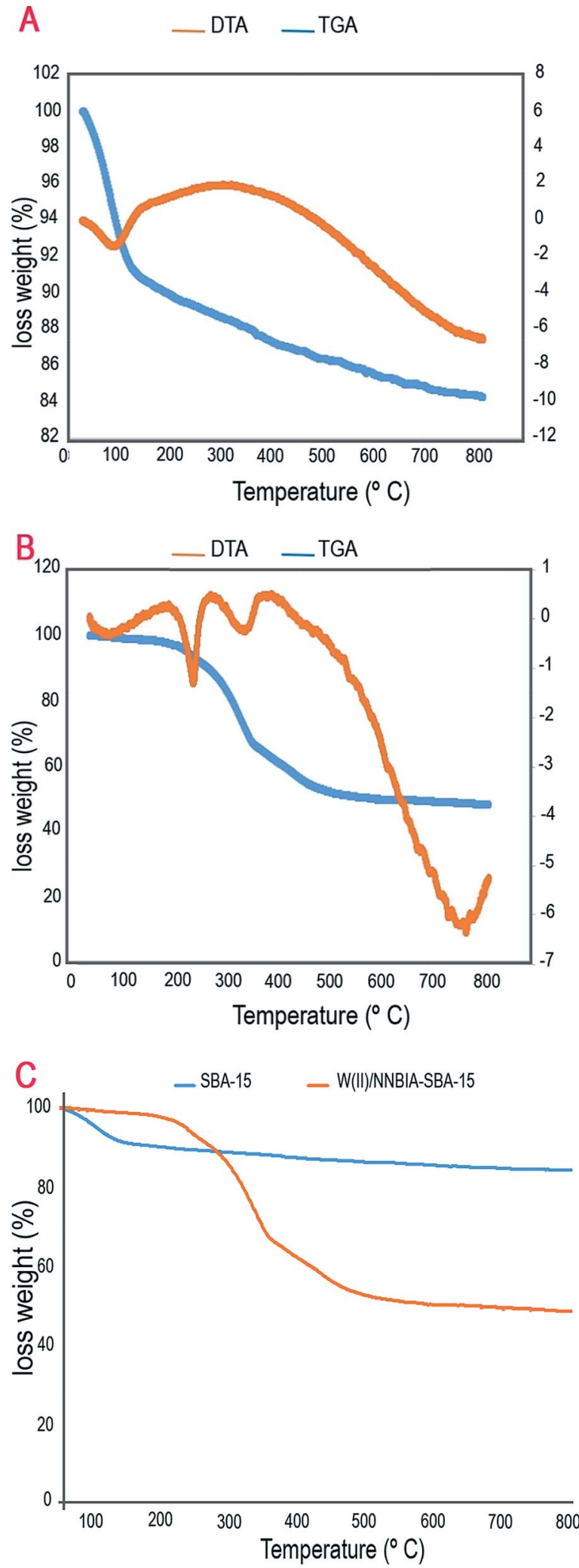

Fig. 6 TGA and DTA curves of (A) SBA-15, and (B) W(IV)/NNBIA-SBA15 and (C) TGA curves of SBA-15 and W(IV)/NNBIA-SBA-15.

the physically adsorbed ammonia and weakly bonded ammonia. The second-wide peak could be assigned to ammonia on the medium-strong acid sites.

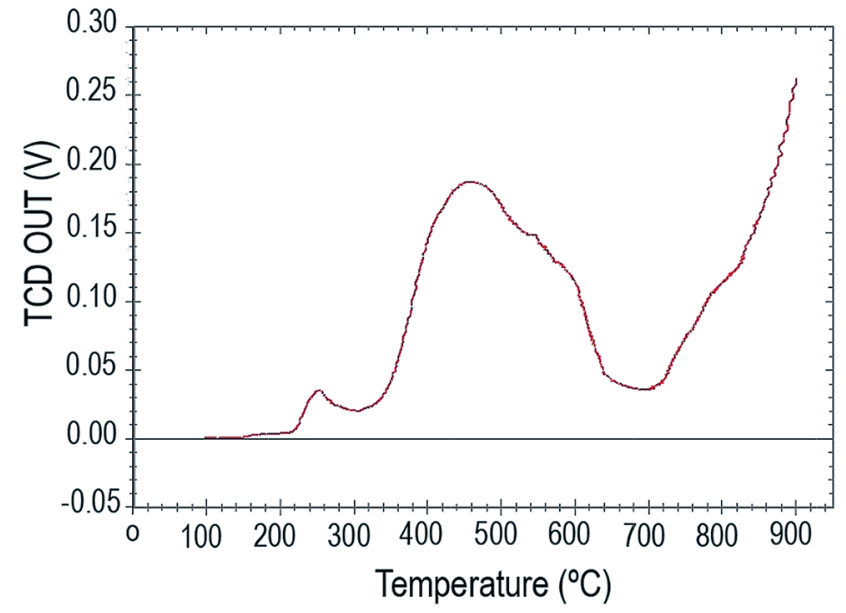

Fig. $7 \mathrm{NH}_{3}$-TPD spectrum of W(IV)/NNBIA-SBA-15.

X-Ray photoelectron spectroscopy was applied to define the electronic state of the tungsten and the atomic concentration of the catalyst. The XPS spectrum of the catalyst shows peaks corresponding to Si, O, C 1s, N 1s, Cl 2s, Cl 2p, and W (Fig. 8F). The $\mathrm{W}$ 4f spectrum shows that the tungsten is present as $\mathrm{W}^{4+}$, with $\mathrm{W} 4 \mathrm{f}_{5 / 2}$ and $\mathrm{W} 4 \mathrm{f}_{7 / 2}$ binding energies of 35 and $33.5 \mathrm{eV}$, respectively, with an approximate intensity ratio of $3: 4$ (ref. 59) (Fig. 8E). The Si 2s and Si 2p peaks are centered at 103 and $150 \mathrm{eV}$ respectively and clearly show the presence of the $\mathrm{SiO}_{2}$ structure $^{60}$ (Fig. 8D). Fig. 8C shows a peak at $285.0 \mathrm{eV}$ for $\mathrm{C} 1 \mathrm{~s}$ to $\pi^{*}(\mathrm{C}=\mathrm{C})$ and $\pi^{*}(\mathrm{C}=\mathrm{N})$ orbitals. ${ }^{61}$ A broad peak extending from 396 to $403 \mathrm{eV}$ is observed for all of the $\mathrm{N}$ contained within the catalyst (Fig. 8B). The $\mathrm{O}$ 1s XPS spectrum shown in Fig. 8A reveals a well-defined peak at $533.52 \mathrm{eV}$ that could be attributed to $\mathrm{SiO}_{2}(533 \mathrm{eV}), \mathrm{C}-\mathrm{O}(531-532 \mathrm{eV})$ and $\mathrm{C}=\mathrm{O}(533 \mathrm{eV})$. Information on the atomic concentration of the W(Iv)/NNBIA-SBA15, as obtained from XPS, is summarized in Table 2.

\subsection{Catalytic tests}

2.2.1. Comparison of the efficiency of W(Iv)/NNBIA-SBA-15 and other catalysts. The merit of the W(Iv)/NNBIA-SBA-15 nanocatalyst was investigated in an MCR reaction. The reaction of isatin, malononitrile, and hydantoin was selected as a model reaction and the results were summarized in Table 3. Almost no corresponding product was obtained in the absence of catalyst after $48 \mathrm{~h}$ under reflux or at $80{ }^{\circ} \mathrm{C}$ in water. We compared the efficiency of homogeneous catalysts such as piperidine, triethylamine, L-proline, DABCO, and $\mathrm{NH}_{2}-\mathrm{SBA}-15$ with W(Iv)/NNBIA-SBA-15. The obtained results indicated that the presence of the nanocatalyst, W(Iv)/NNBIA-SBA-15, was much more efficient than previously reported homogenous basic catalysts (Table 3 , entries $3-7$ ). The adsorption of reactants on the surface of the nanocatalyst support increased the local concentration of reactants around the active sites of W(Iv)/ NNBIA-SBA-15. The effect of functionalization was evaluated using SBA-15 alone. The results indicated that SBA-15 alone was almost inactive, which is probably due to the absence of active sites (Table 3, entries 7 and 8). The effect of the metal was 

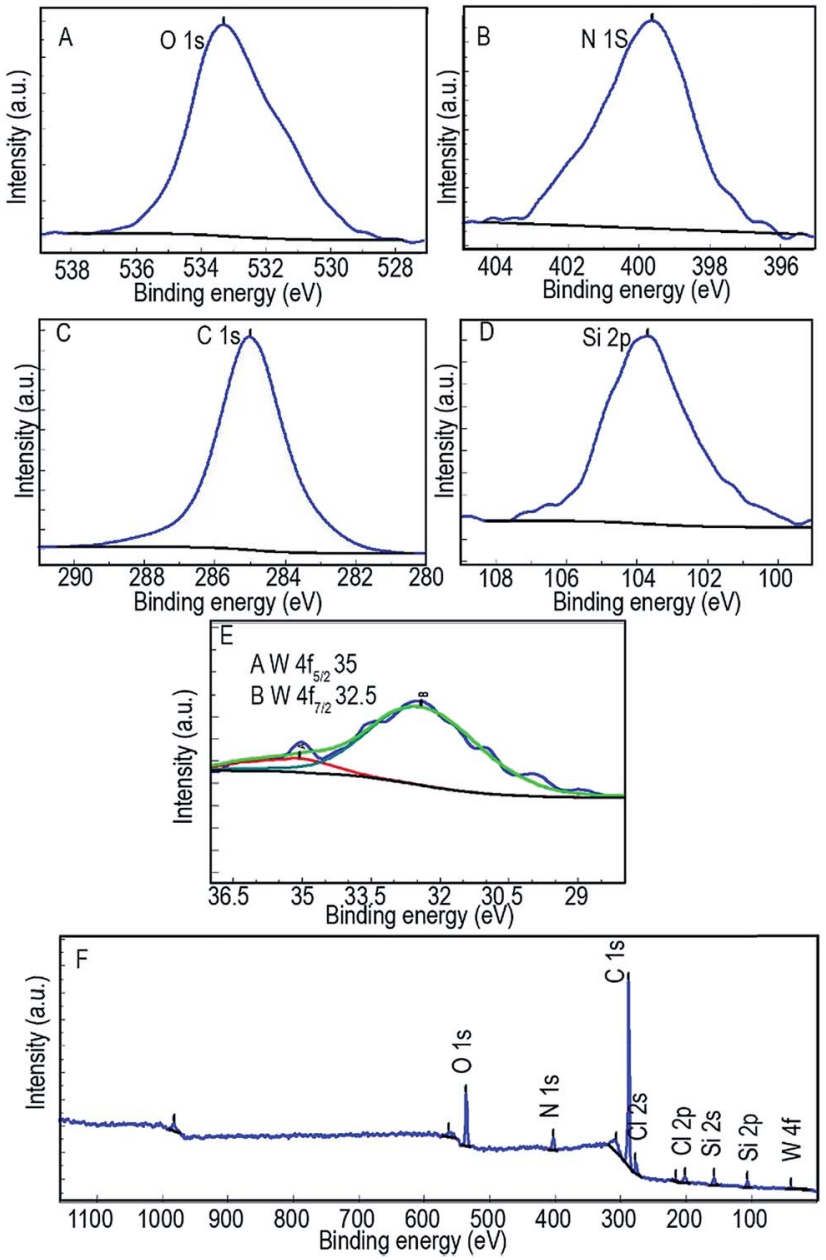

Fig. 8 XPS spectra of (A) O 1s, (B) N 1s, (C) C 1s, (D) Si 2p, (E) W $4 f$ and (F) W(IV)/NNBIA-SBA-15.

Table 2 Results of XPS elemental analysis in \% for W(IV)/NNBIA-SBA15

\begin{tabular}{lllllll}
\hline Sample & O & N & C & Cl & Si & W \\
\hline W(Iv)/NNBIA-SBA-15 (\%) & 11.0 & 5.0 & 78.0 & 1.8 & 4.0 & 0.1
\end{tabular}

investigated. Based on the results, the absence of metal in the catalyst decreased the yield and increased the time of the reaction (Table 3, entries 7 and 9). $\mathrm{WCl}_{6}$ alone provided the desired product in a $50 \%$ yield which points to the importance of the presence of the support and the ligand (Table 3, entries 7 and 10).

2.2.2. Effect of solvent, temperature and catalyst amount on the synthesis of 2-azapyrrolizidine alkaloids. The effect of water and organic solvents such as $\mathrm{EtOH}, \mathrm{PhCH}_{3}, \mathrm{CH}_{3} \mathrm{CN}$, and DMF were studied on the sequential one-pot reaction (Table 4, entries 1-6). In the presence of polar solvents such as $\mathrm{H}_{2} \mathrm{O}$ and $\mathrm{EtOH}$, the product was synthesized in excellent yields, although a gummy solid was obtained with EtOH. The best results were obtained using water in terms of both yield and time. Thus we kept this as the optimal solvent for the subsequent reactions.
Table 3 The effect of the different catalysts on the synthesis of 2azapyrrolizidine alkaloids

\begin{tabular}{|c|c|c|c|}
\hline Entry & Catalyst $^{a}$ & Time (h) & Yield $^{b}(\%)$ \\
\hline 1 & No catalyst (reflux) & 48 & Trace \\
\hline 2 & No catalyst & 48 & Trace \\
\hline 3 & Piperidine (20 mol\%) & 8 & 50 \\
\hline 4 & $\mathrm{NEt}_{3}(20 \mathrm{~mol} \%)$ & 7 & 75 \\
\hline 5 & L-Prolin (20 mol\%) & 15 & 32 \\
\hline 6 & DABCO $(20 \mathrm{~mol} \%)$ & 8 & 17 \\
\hline 7 & W(Iv)/NNBIA-SBA-15 (0.03 g) & 3 & 95 \\
\hline 8 & SBA-15 & 18 & $\geq 20$ \\
\hline 9 & NNBIA-SBA-15 & 18 & 40 \\
\hline 10 & $\mathrm{WCl}_{6}$ & 12 & 50 \\
\hline
\end{tabular}

${ }^{a}$ Reactions conditions: isatin $(1 \mathrm{mmol})$, malononitrile $(1 \mathrm{mmol})$, and hydantoin $(1 \mathrm{mmol})$ in water at $80{ }^{\circ} \mathrm{C} .{ }^{b}$ Isolated yield.

The temperature had the greatest effect on the reaction progress. A trace amount of product was yielded at room temperature after $48 \mathrm{~h}$, and the results of the reflux conditions were not appropriate (Table 4, entries 6-8). The best results were obtained at $80{ }^{\circ} \mathrm{C}$.

The influence of the catalyst amount was studied under the optimum conditions (Table 4, entries 8-10). An acceptable reaction time and yield were obtained by loading $0.03 \mathrm{~g}$ of catalyst, and no benefit was observed with a greater catalyst amount.

2.2.3. Synthesis of 2-azapyrrolizidine alkaloids derivatives in the presence of $\mathrm{W}(\mathrm{Iv}) / \mathrm{NNBIA-SBA-15}$ under optimized conditions. The crucial characteristics of the new organicinorganic catalyst, W(Iv)/NNBIA-SBA-15, are chemical stability, reusability, and non-toxicity. The efficiency of the catalyst was tested for the synthesis of a broad range of 2-azapyrrolizidine alkaloids. The methodology was explored by using various carbonyl derivatives $(1 \mathrm{mmol})$, malononitrile $(1 \mathrm{mmol})$ and hydantoin $(1 \mathrm{mmol})$, under optimized conditions. In the presence of various isatin compounds, the desired products were obtained in good yield and diastereoselectivity (Table 5). Furthermore, the results of the scope of the reaction showed that the reaction progressed well with different aldehydes with electron donating and electron withdrawing groups substituted (Table 6).

\subsection{Characterization of the products of the three component reactions}

High diastereoselectivity can be observed by using aldehydes to produce only the trans diastereomer. The MCR reaction causes the generation of a cis-fused 2-azapyrrolizidine. Actually, the two hydrogens attached to the adjacent chiral carbon are trans. In the presence of isatin, a highly strained spirooxindole with a quaternary stereocenter was generated in only one diastereomer of a racemic mixture. The regioselectivity of the reaction can be rationalized by analysing the structure of hydantoin. Scheme 2 shows that hydantoin can play either the role of a 1,3binucleophile when using the $\left(\mathrm{CH}_{2}\right)$ and the $(\mathrm{O})$ of the amide moiety or the role of a 1,2-binucleophile when using the $\left(\mathrm{CH}_{2}\right)$ 
Table 4 Optimization of solvent, temperature and catalyst amount for the synthesis of 2-azapyrrolizidine alkaloids

\begin{tabular}{|c|c|c|c|c|c|}
\hline Entry $^{a}$ & Solvent & Temp. $\left({ }^{\circ} \mathrm{C}\right)$ & $\begin{array}{l}\text { Catalyst amount } \\
(\mathrm{g})\end{array}$ & Time (h) & Yield $^{b}(\%)$ \\
\hline 1 & $\mathrm{CH}_{3} \mathrm{CN}$ & Reflux & 0.03 & 12 & 72 \\
\hline 3 & DMF & Reflux & 0.03 & 12 & 24 \\
\hline 4 & EtOH & Reflux & 0.03 & 4 & 83 \\
\hline 5 & EtOH-water & Reflux & 0.03 & 4 & 85 \\
\hline 8 & Water & 80 & 0.03 & 3 & 95 \\
\hline 9 & Water & 80 & 0.02 & 4 & 80 \\
\hline 10 & Water & 80 & 0.04 & 4 & 95 \\
\hline
\end{tabular}

Table 5 Synthesis of spirooxindole-2-azapyrrolizidine derivatives

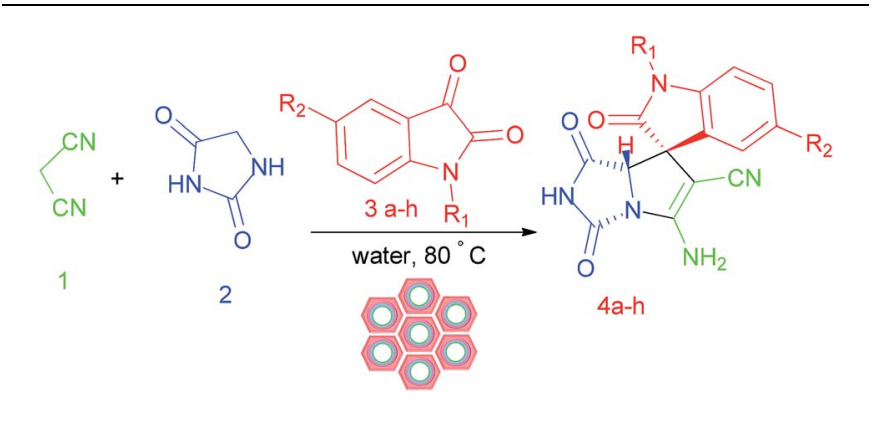

\begin{tabular}{|c|c|c|c|c|c|c|}
\hline \multirow[b]{2}{*}{ Entry $^{a}$} & \multicolumn{2}{|c|}{$\begin{array}{l}\text { Isatin 1a- } \\
\mathbf{g} \\
\end{array}$} & \multirow[b]{2}{*}{ Product $\mathbf{4 a - h}$} & \multirow[b]{2}{*}{ Time (h) } & \multirow[b]{2}{*}{ Yield $^{b}(\%)$} & \multirow[b]{2}{*}{$\mathrm{mp}\left({ }^{\circ} \mathrm{C}\right)$} \\
\hline & $R_{1}$ & $R_{2}$ & & & & \\
\hline 1 & $\mathrm{H}$ & $\mathrm{H}$ & $4 a$ & 3 & 95 & 260 \\
\hline 2 & $\mathrm{Me}$ & $\mathrm{H}$ & $4 b$ & 4 & 85 & 280 \\
\hline 3 & $\mathrm{H}$ & $\mathrm{Cl}$ & $4 c$ & 4 & 80 & 300 \\
\hline 4 & $\mathrm{H}$ & $\mathrm{F}$ & $4 d$ & 5 & 79 & 304 \\
\hline 5 & $\mathrm{H}$ & $\mathrm{Br}$ & $4 e$ & 5 & 90 & 318 \\
\hline 6 & $\mathrm{H}$ & I & 4f & 5 & 85 & 291 \\
\hline 7 & $\mathrm{H}$ & $\mathrm{NO}_{2}$ & $4 \mathrm{~g}$ & 6 & 78 & 340 \\
\hline 8 & $\mathrm{H}$ & $\mathrm{OMe}$ & $4 h$ & 5 & 90 & 271 \\
\hline
\end{tabular}

and the adjacent (NH). Pyrano-spirooxindole (A) is the corresponding product if hydantoin reacts as a 1,3-binucleophile and product $4 \mathbf{k}$ is expected if hydantoin reacts as a 1,2-binucleophile. Structure $\mathbf{4 k}$ was confirmed by ${ }^{1} \mathrm{H}$ NMR spectroscopy. It indicates exchangeable protons at 11.67, 10.60 and $7.76 \mathrm{ppm}$ with a $1: 1: 2$ ratio, that can be referenced to two types of $(\mathrm{NH})$ and an $\left(\mathrm{NH}_{2}\right)$ respectively. In addition, the ${ }^{1} \mathrm{H}$ NMR shows 1 proton for the one singlet at $5.11 \mathrm{ppm}$ which is matched by the structure of $\mathbf{4 k}$.

\subsection{A plausible mechanism for the preparation of 2- azapyrrolizidine alkaloids}

A plausible catalytic cycle for the present reaction is illustrated in Scheme 3. The electrophilicity of malononitrile is increased
Table 6 Synthesis of 2-azapyrrolizidine derivatives
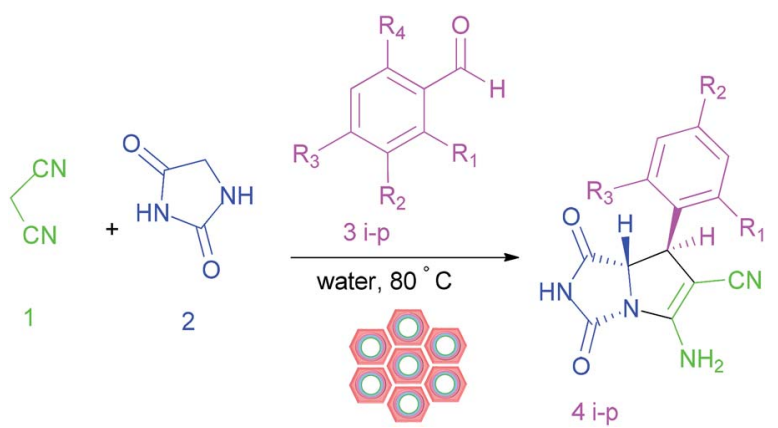

Aldehyde

\begin{tabular}{llllllll} 
Entry $^{a}$ & $R_{1}$ & $R_{2}$ & $R_{3}$ & $R_{4}$ & Product & Time (h) Yield $^{b}(\%)$ & $\mathrm{mp}\left({ }^{\circ} \mathrm{C}\right)$ \\
\hline
\end{tabular}

\begin{tabular}{llllllllll}
\hline 1 & $\mathrm{H}$ & $\mathrm{H}$ & OMe & $\mathrm{H}$ & $\mathbf{4 i}$ & 3 & 95 & 260
\end{tabular}

$\begin{array}{lllllllll}2 & \mathrm{H} & \mathrm{H} & \mathrm{Me} & \mathrm{H} & \mathbf{4 j} & 3 & 95 & 260\end{array}$

$\begin{array}{lllllllll}3 & \mathrm{H} & \mathrm{H} & \mathrm{H} & \mathrm{H} & \mathbf{4 k} & 1 & 92 & 275\end{array}$

$\begin{array}{lllllllll}4 & \text { OMe } & \text { H } & \text { OMe } & \text { H } & \text { 4l } & 6 & 50 & 245\end{array}$

$\begin{array}{llllllll}5 & \mathrm{H} & \mathrm{H} & \mathrm{Br} & \mathrm{H} & \mathbf{4 m} & 74 & 271\end{array}$

$\begin{array}{lllllllll}6 & \mathrm{H} & \mathrm{NO}_{2} & \mathrm{H} & \mathrm{H} & 4 \mathbf{n} & 6 & 85 & 265\end{array}$

$\begin{array}{llllllll}7 & \mathrm{H} & \mathrm{Cl} & \mathrm{H} & \mathbf{4 0} & 2 & 96 & 281\end{array}$

${ }^{a}$ Reactions conditions: aldehyde derivatives ( $\left.1 \mathrm{mmol}\right)$, malononitrile (1 $\mathrm{mmol})$, and hydantoin $(1 \mathrm{mmol}) .{ }^{b}$ Isolated yield.

by coordination with the $\mathrm{W}(\mathrm{rv}) / \mathrm{NNBIA-SBA}-15$. The nitrile is coordinated to a tungsten site which is followed by a mechanism involving a proton abstraction, and a stable hydrido(enolato)-complex (A) is afforded. ${ }^{62}$ Then the Knoevenagel condensations of (A) with carbonyl group derivatives are carried out to produce the cyano olefins (B1) and (C1). Deprotonations of the cyano olefins (B1) and (C1) take place at the amino groups distributed on the surface of W(Iv)/NNBIA-SBA-15 to yield the nucleophiles. On the other hand, coordination of the carbonyl groups of hydantoin to a tungsten site of the $\mathrm{W}(\mathrm{Iv}) /$ NNBIA-SBA-15 activates the electrophile in close proximity to the nucleophile. As the second step, a Michael addition occurs to generate intermediates (B2) and (C2) ${ }^{63}$ They are held in close 


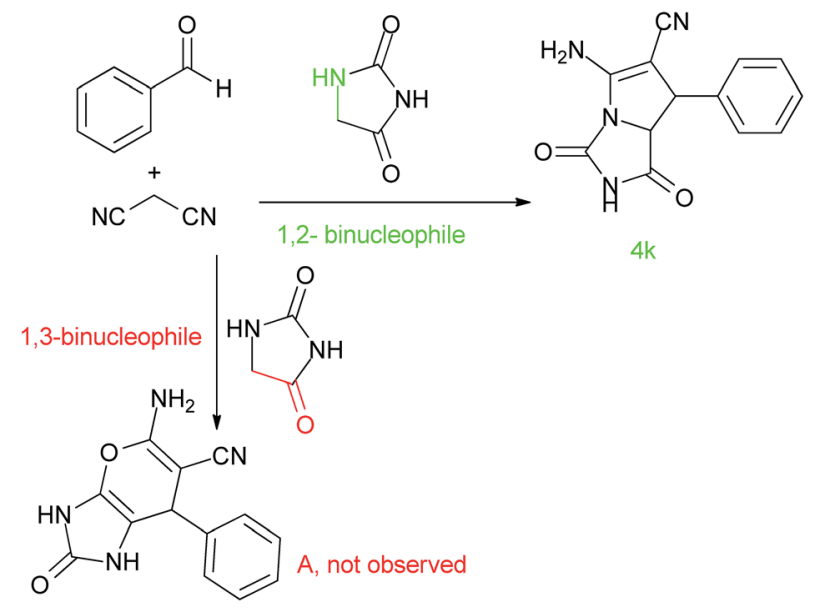

Scheme 2 Investigation on the structure of hydantoin.

proximity to the W(Iv)/NNBIA-SBA-15 through coordination of the carbonyl groups of hydantoin to a tungsten site of the $\mathrm{W}(\mathrm{IV}) /$ NNBIA-SBA-15. Then, the reaction might follow either a 5-exodig or 6-exo-dig pathway. However, the reactions are chemoselective and the corresponding products were achieved by 5 exo-dig. The amino groups distributed on the surface of W(Iv)/ NNBIA-SBA-15 provide a nucleophilic mechanism. Tungsten sites at the surface of the nanocatalyst increase the electrophilicity of the reactants. The high surface area of the SBA-15 is very important for the high turnover frequency of the reaction. The role of water as the solvent was evaluated. Water molecules form $\mathrm{H}$-bonds with organic reactants that have hydrogen bond acceptor sites, both in their initial states and in their reaction transition states. $\mathrm{H}$-bonding reduces the energy of the frontier orbitals by decreasing interorbital repulsion and electron density. ${ }^{64}$

\subsection{Hot filtration test for the W(Iv)/NNBIA-SBA-15 catalyst}

We did a hot filtration test to prove that the organic moiety was attached to SBA-15 by covalent bonding that leads to stable attachment and less leaching. This test was carried out on the model reaction in the presence of $0.03 \mathrm{~g}$ of W(Iv)/NNBIA-SBA-15 at $80{ }^{\circ} \mathrm{C}$ for $30 \mathrm{~min}$. The reaction was continued for another $30 \mathrm{~min}$ in the absence of the catalyst and the yield of the product did not improve. Based on the results, the heterogeneity, the leaching-resistant properties and the stability of the W(Iv)/NNBIA-SBA-15 catalyst have been confirmed.

\subsection{Reusability of the W(Iv)/NNBIA-SBA-15 catalyst}

The model reaction with isatin $(1 \mathrm{mmol})$, malononitrile (1 $\mathrm{mmol})$, and hydantoin ( $1 \mathrm{mmol}$ ) was also employed to examine the reusability of the nanocatalyst, W(Iv)/NNBIA-SBA-15. After the accomplishment of the reaction, the catalyst was filtered and washed with $5 \mathrm{~mL}$ hot ethanol $(3 \times 10 \mathrm{~mL})$ and water $(2 \times 5$

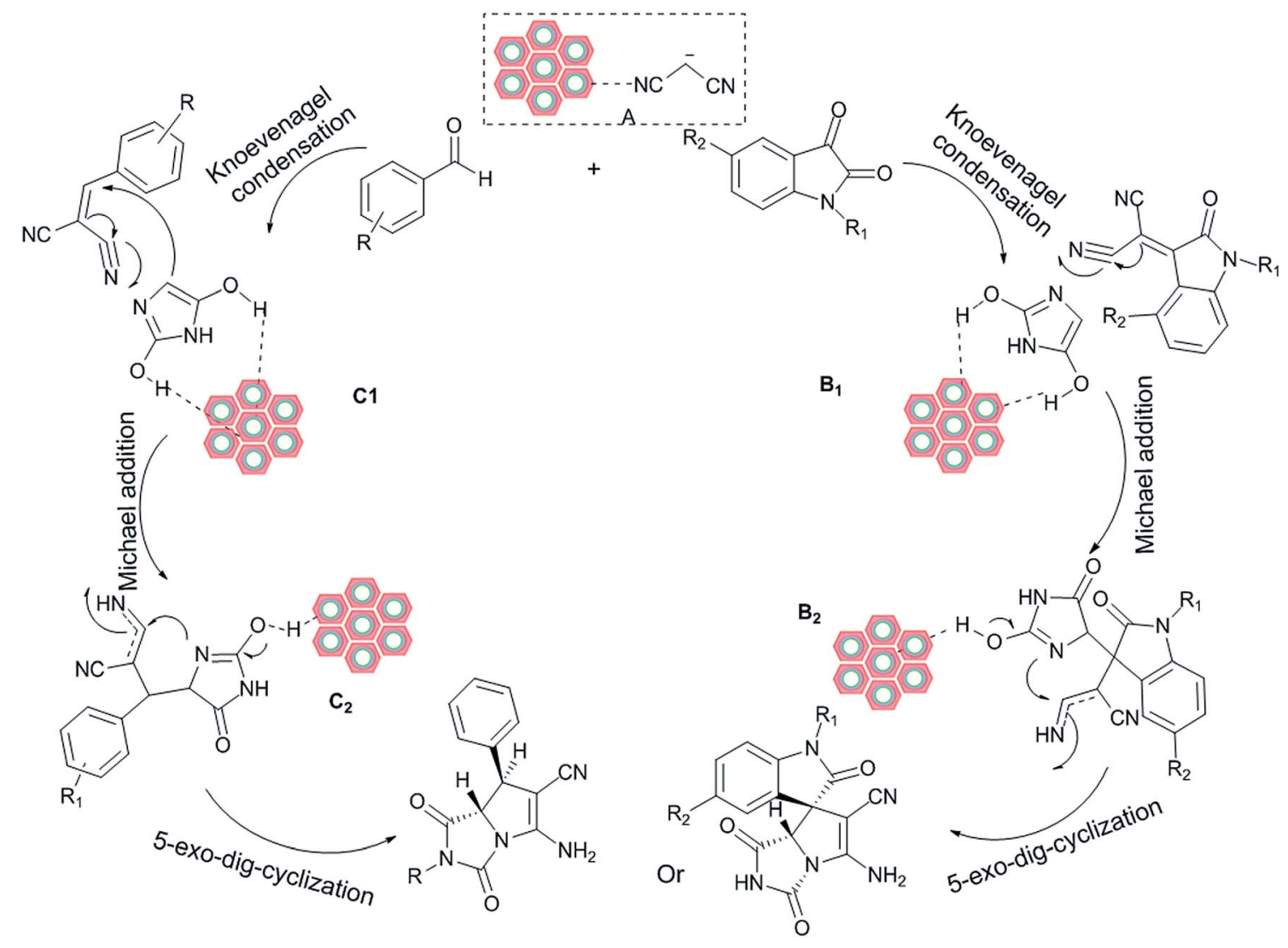

Scheme 3 The proposed mechanism for the synthesis of azapyrrolizidine alkaloids. 


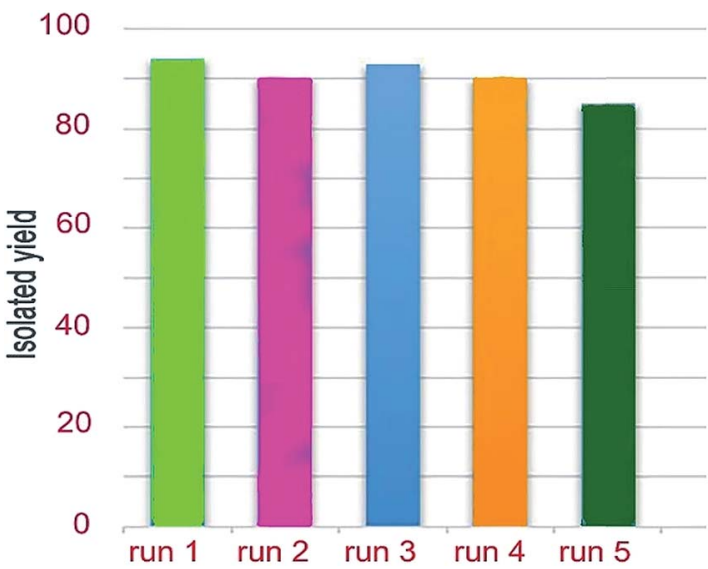

Fig. 9 Recyclability study of the nanocatalyst, W(Iv)/NNBIA-SBA-15, for the reaction of isatin $(1 \mathrm{mmol})$, malononitrile $(1 \mathrm{mmol})$ and hydantoin $(1 \mathrm{mmol})$ under optimized conditions.

$\mathrm{mL}$ ) and reused in a new reaction. However, in the second run, the conversion under similar conditions had a negligible reduction due to the blockage of catalytic sites with the reactants (Fig. 9). After the second run, the reused catalyst was washed three times with $5 \mathrm{~mL}$ hot ethanol $(3 \times 10 \mathrm{~mL})$ and water $(2 \times 5 \mathrm{~mL})$ to remove residual reactants and that resulted in the restoration of activity of the catalyst. In the third run, the reaction yield was improved by using the reused catalyst. Based upon these results, it was found that the W(Iv)/NNBIA complex was strongly anchored on the mesoporous supports, and the catalytic activity did not decrease.

\subsection{Study of the spectral data of some representative 2-} azapyrrolizidine alkaloid scaffolds

2.7.1 4a: (trans-3,7a')-5' -amino-1' $\mathbf{1}^{\prime}, 2,3^{\prime}$-trioxo1 ${ }^{\prime}, 2^{\prime}, 3^{\prime}, 7 \mathbf{a}^{\prime}$-tetrahydro spiro[indoline- $3,7^{\prime}$-pyrrolo $[1,2-c]$ imidazole $]-6^{\prime}$-carbonitrile. $\mathrm{mp}=260-262{ }^{\circ} \mathrm{C}$; IR $\left(\mathrm{KBr}, \mathrm{cm}^{-1}\right)=3372,3341,3252$, 3200, 2182, 1791, 1738, 1702, 1656, 1620; ${ }^{1} \mathrm{H}$ NMR $(400 \mathrm{MHz}$, DMSO-d $\left.\mathrm{d}_{6}\right): \delta=11.680(\mathrm{~s}, 1 \mathrm{H}, \mathrm{NH}), 10.609(\mathrm{~s}, 1 \mathrm{H}, \mathrm{NH}), 7.775$ (br, s, 2H, $\mathrm{NH}_{2}$ ), $7.408(\mathrm{~d}, J=8 \mathrm{~Hz}, 1 \mathrm{H}), 7.253(\mathrm{t}, J=8 \mathrm{~Hz}, 1 \mathrm{H})$, 7.049 (t, $J=8 \mathrm{~Hz}, 1 \mathrm{H}), 6.853$ (d, $J=8 \mathrm{~Hz}, 1 \mathrm{H}), 5.11(\mathrm{~s}, 1 \mathrm{H}, \mathrm{CH})$; anal. calcd for $\mathrm{C}_{14} \mathrm{H}_{9} \mathrm{~N}_{5} \mathrm{O}_{3}: \mathrm{C}, 56.45 ; \mathrm{H}, 3.07 ; \mathrm{N}, 23.72$; found: $\mathrm{C}$, 56.99 ; H, 3.12; N, 23.78; HR-MS $m / z$ : calcd for $\mathrm{C}_{14} \mathrm{H}_{9} \mathrm{~N}_{5} \mathrm{O}_{3}[\mathrm{M}+$ $\mathrm{Na}^{+}$: 318.0603; found: 318.0609.

2.7.2 4b: $\quad\left(\right.$ trans-3,7a')-5' -amino-1-methyl-1' ${ }^{\prime}, 2,3^{\prime}$-trioxo$1^{\prime}, 2^{\prime}, 3^{\prime}, 7 a^{\prime}$-tetrahydrospiro[indoline-3, $7^{\prime}$-pyrrolo[1,2-c]imid-

azole]-6'-carbonitrile. $\mathrm{mp}=280{ }^{\circ} \mathrm{C}$; IR $\left(\mathrm{KBr}, \mathrm{cm}^{-1}\right): 3552,3501$, 3210, 2928, 2187, 1790, 1742, 1688, 1648; ${ }^{1} \mathrm{H}$ NMR $(400 \mathrm{MHz}$, DMSO-d ${ }_{6}$ ): $\delta=11.04$ (br, 1H, NH), 7.741 (br, 2H, $\mathrm{NH}_{2}$ ), 7.526 (d, $J=7.5 \mathrm{~Hz}, 1 \mathrm{H}), 7.339(\mathrm{t}, J=7.5 \mathrm{~Hz}, 1 \mathrm{H}), 7.108(\mathrm{t}, J=7.5 \mathrm{~Hz}, 1 \mathrm{H})$, $7.072(\mathrm{~d}, J=7.5 \mathrm{~Hz}, 1 \mathrm{H}), 5.094(\mathrm{~s}, 1 \mathrm{H}, \mathrm{CH}), 3.019\left(\mathrm{~s}, 3 \mathrm{H}, \mathrm{CH}_{3}\right)$; anal. calcd for $\mathrm{C}_{15} \mathrm{H}_{11} \mathrm{~N}_{5} \mathrm{O}_{3}: \mathrm{C}, 58.14 ; \mathrm{H}, 3.72 ; \mathrm{N}, 22.59$; found: $\mathrm{C}$, $58.02 ; \mathrm{H}, 3.52 ; \mathrm{N}, 22.21$; HR-MS $m / z$ : calcd for $\mathrm{C}_{15} \mathrm{H}_{11} \mathrm{~N}_{5} \mathrm{O}_{3}[\mathrm{M}+$ $\mathrm{Na}]^{+}$: 332.0759; found: 332.0762.

2.7.3 4c: $\quad\left(\right.$ trans-3,7a')-5' -amino-5-chloro-1' ${ }^{\prime}, 2,3^{\prime}$-trioxo$1^{\prime}, 2^{\prime}, 3^{\prime}, 7 a^{\prime}$-tetrahydrospiro[indoline-3,7'-pyrrolo[1,2-c]imidazole]-6'-carbonitrile. $\mathrm{mp}=300{ }^{\circ} \mathrm{C}$; $\mathrm{IR}\left(\mathrm{KBr}, \mathrm{cm}^{-1}\right)$ : 3493, 3392,
3237, 2750, 2197, 1790, 1742, 1700, 1636, 1572; ${ }^{1} \mathrm{H}$ NMR (400 MHz, DMSO-d ${ }_{6}$ ): $\delta=11.057$ (br, 1H, NH), 10.749 (br, 1H, NH), 7.831 (br, 2H, $\mathrm{NH}_{2}$ ), 7.568 (s, 1H), 7.333 (d, J=7.2 Hz, 1H), 6.882 $(\mathrm{d}, J=7.2 \mathrm{~Hz}, 1 \mathrm{H}), 5.168(\mathrm{~s}, 1 \mathrm{H}, \mathrm{CH}) ; \mathrm{C}_{14} \mathrm{H}_{8} \mathrm{ClN}_{5} \mathrm{O}_{3}: \mathrm{C}, 51.12 ; \mathrm{H}$, 2.64; N, 21.32; found: C, 51.23; H, 2.34; N, 21.17; HR-MS $m / z$ : calcd for $\mathrm{C}_{14} \mathrm{H}_{8} \mathrm{ClN}_{5} \mathrm{O}_{3}[\mathrm{M}+\mathrm{Na}]^{+}$: 352.0213; found: 352.0216 .

2.7.4 4d: $\quad\left(\right.$ trans-3,7a')-5' -amino-5-bromo-1' ${ }^{\prime}, 2,3^{\prime}$-trioxo$\mathbf{1}^{\prime}, \mathbf{2}^{\prime}, 3^{\prime}, 7 \mathrm{a}^{\prime}$-tetrahydrospiro[indoline-3,7'-pyrrolo[1,2-c]imid-

azole]-6'-carbonitrile. $\mathrm{mp}=304{ }^{\circ} \mathrm{C}$; IR $\left(\mathrm{KBr}, \mathrm{cm}^{-1}\right)$ : 3485, 3385, 3243 , 3150, 2736, 2193, 1790, 1744, 1707, 1634; ${ }^{1} \mathrm{H}$ NMR (400 MHz, DMSO-d $\mathrm{d}_{6}$ ): $\delta=12.45$ (br, $\left.1 \mathrm{H}, \mathrm{NH}\right), 11.127$ (br, $1 \mathrm{H}, \mathrm{NH}$ ), $7.728\left(\mathrm{br}, 2 \mathrm{H}, \mathrm{NH}_{2}\right), 7.708$ (d, $\left.J=7.5 \mathrm{~Hz}, 1 \mathrm{H}\right), 7.288(\mathrm{~s}, 1 \mathrm{H}), 6.865$ (d, $J=7.5 \mathrm{~Hz}, 1 \mathrm{H}), 5.150(\mathrm{~s}, 1 \mathrm{H}, \mathrm{CH})$; anal. calcd for $\mathrm{C}_{14} \mathrm{H}_{8} \mathrm{BrN}_{5} \mathrm{O}_{3}$ : C, 44.82; H, 2.13; N, 18.61; found: C, 44.70; $\mathrm{H}$, 2.53; N, 18.83. HR-MS $m / z$ : calcd for $\mathrm{C}_{14} \mathrm{H}_{8} \mathrm{BrN}_{5} \mathrm{O}_{3}[\mathrm{M}+\mathrm{Na}]^{+}$: 395.9708; found: 395.9709 .

2.7.5 4e: $\quad\left(\right.$ trans-3,7a')-5' $\mathbf{5}^{\prime}$-amino-5-fluoro-1' $\mathbf{1}^{\prime}, 2,3^{\prime}$-trioxo$\mathbf{1}^{\prime}, 2^{\prime}, 3^{\prime}, 7 \mathbf{a}^{\prime}$-tetrahydrospiro[indoline-3,7'-pyrrolo[1,2-c]imidazole]-6 $6^{\prime}$-carbonitrile. $\mathrm{mp}=318^{\circ} \mathrm{C}$; $\mathrm{IR}\left(\mathrm{KBr}, \mathrm{cm}^{-1}\right)=3378,3200$, 2186, 1794, 1712, 1662, 1601; ${ }^{1} \mathrm{H}$ NMR $\left(400 \mathrm{MHz}, \mathrm{DMSO}_{\mathrm{d}}\right): \delta=$ 11.697 (s, 1H, NH), $10.643(\mathrm{~s}, 1 \mathrm{H}, \mathrm{NH}), 7.83\left(\mathrm{br}, 2 \mathrm{H}, \mathrm{NH}_{2}\right), 7.44$ $(\mathrm{d}, J=8.4,1 \mathrm{H}), 7.16-7.11(\mathrm{~m}, 1 \mathrm{H}), 6.88(\mathrm{~d}, J=8.4,1 \mathrm{H}), 5.16(\mathrm{~s}$, $1 \mathrm{H}, \mathrm{CH}$ ); anal. calcd for $\mathrm{C}_{14} \mathrm{H}_{8} \mathrm{FN}_{5} \mathrm{O}_{3}$ : C, 53.68; H, 2.57; N, 22.36; found: $\mathrm{C}, 53.52 ; \mathrm{H}, 2.59 ; \mathrm{N}, 22.42 ; \mathrm{HR}-\mathrm{MS} \mathrm{m} / \mathrm{z}$ : calcd for $\mathrm{C}_{14} \mathrm{H}_{8} \mathrm{FN}_{5} \mathrm{O}_{3}[\mathrm{M}+\mathrm{Na}]^{+}$: 336.0508; found: 336.0509.

2.7.6 4f: $\quad\left(\right.$ trans $\left.-3,7 \mathrm{a}^{\prime}\right)-5^{\prime}$-amino-5-iodo- $\mathbf{1}^{\prime}, 2,3^{\prime}$-trioxo$1^{\prime}, 2^{\prime}, 3^{\prime}, 7 a^{\prime}$-tetrahydrospiro[indoline-3,7' -pyrrolo[1,2-c]imidazole]-6'-carbonitrile. $\mathrm{mp}=291{ }^{\circ} \mathrm{C}$; IR $\left(\mathrm{KBr}, \mathrm{cm}^{-1}\right)$ : 3375, 3346, 3258, 3204, 2192, 1798, 1743, 1712, 1660, 1623; ${ }^{1} \mathrm{H}$ NMR (400 MHz, DMSO-d $\left.\mathrm{d}_{6}\right): \delta=11.71(\mathrm{~s}, 1 \mathrm{H}), 10.73(\mathrm{~s}, 1 \mathrm{H}), 7.83(\mathrm{br}, \mathrm{s}, 2 \mathrm{H})$, $7.80(\mathrm{~d}, J=1.6 \mathrm{~Hz}, 1 \mathrm{H}), 7.63(\mathrm{q}, J=8.4,8.0 \mathrm{~Hz}, 1 \mathrm{H}), 5.18(\mathrm{~s}, 1 \mathrm{H})$; anal. calcd for $\mathrm{C}_{14} \mathrm{H}_{8} \mathrm{IN}_{5} \mathrm{O}_{3}$ : C, 39.91; $\mathrm{H}, 3.37 ; \mathrm{N}, 21.42$; found: $\mathrm{C}$, 40.01; $\mathrm{H}, 3.38 ; \mathrm{N}, 21.39$. HR-MS $m / z$ : calcd for $\mathrm{C}_{14} \mathrm{H}_{8} \mathrm{IN}_{5} \mathrm{O}_{3}[\mathrm{M}+$ $\mathrm{Na}]^{+}:$443.9568; found: 443.9570 .

2.7.7 4g: $\quad\left(\right.$ trans-3,7a')-5' -amino-5-nitro-1' ${ }^{\prime}, 2,3^{\prime}$-trioxo$1^{\prime}, 2^{\prime}, 3^{\prime}, 7 a^{\prime}$-tetrahydrospiro[indoline-3,7'-pyrrolo[1,2-c]imid-

azole]-6'-carbonitrile. $\mathrm{mp}=340{ }^{\circ} \mathrm{C}$; IR $\left(\mathrm{KBr}, \mathrm{cm}^{-1}\right)=3499,3424$, $3302,3195,2200,1807,1785,1751,1735,1722,1650,1628 ;{ }^{1} \mathrm{H}$ NMR (400 MHz, DMSO-d ${ }_{6}$ ): $\delta=11.648(\mathrm{br}, 1 \mathrm{H}, \mathrm{NH}), 11.283(\mathrm{br}$, $1 \mathrm{H}, \mathrm{NH}), 8.440(\mathrm{~d}, J=8 \mathrm{~Hz}, 1 \mathrm{H}), 8.20(\mathrm{~s}, 1 \mathrm{H}), 7.640\left(\mathrm{br} \mathrm{s}, \mathrm{NH}_{2}\right)$, $7.066(\mathrm{~d}, J=8 . \mathrm{Hz}, 1 \mathrm{H}), 5.437(\mathrm{~s}, 1 \mathrm{H}, \mathrm{CH})$; anal. calcd for $\mathrm{C}_{14} \mathrm{H}_{8} \mathrm{~N}_{6} \mathrm{O}_{5}$ : C, 49.41; H, 2.36; N, 24.69; found: $\mathrm{C}, 50.01 ; \mathrm{H}$, 2.48; N, 24.52. HR-MS $m / z$ : calcd for $\mathrm{C}_{14} \mathrm{H}_{8} \mathrm{~N}_{6} \mathrm{O}_{5}[\mathrm{M}+\mathrm{Na}]^{+}$: 363.0453; found: 363.0455 .

2.7.8 4h: $\quad\left(\right.$ trans-3,7a')-5'-amino-5-methoxy-1' $\mathbf{1}^{\prime}, 2,3^{\prime}$-trioxo$\mathbf{1}^{\prime}, 2^{\prime}, 3^{\prime}, 7 \mathbf{a}^{\prime}$-tetrahydrospiro[indoline-3,7'-pyrrolo[1,2-c]imid-

azole]-6'-carbonitrile. $\mathrm{mp}=265{ }^{\circ} \mathrm{C}$; IR $\left(\mathrm{KBr}, \mathrm{cm}^{-1}\right)$ : 3377, 3325, $3267,2895,2187,1801,1748,1720,1659,1593 ;{ }^{1} \mathrm{H}$ NMR (400 MHz, DMSO-d $\left.{ }_{6}\right): \delta=11.67(\mathrm{br}, 1 \mathrm{H}, \mathrm{NH}), 10.42(\mathrm{br}, 1 \mathrm{H}, \mathrm{NH}), 7.76$ (br, 2H, $\left.\mathrm{NH}_{2}\right), 7.10(\mathrm{~d}, J=8.4 \mathrm{~Hz}, 1 \mathrm{H}), 6.84(\mathrm{~d}, J=8.4,1 \mathrm{H}), 6.77$ $(\mathrm{d}, J=8.4 \mathrm{~Hz}, 1 \mathrm{H}), 5.12(\mathrm{~s}, 1 \mathrm{H}, \mathrm{CH}), 3.73\left(\mathrm{~s}, 3 \mathrm{H}, \mathrm{OCH}_{3}\right)$; anal. calcd for $\mathrm{C}_{15} \mathrm{H}_{11} \mathrm{~N}_{5} \mathrm{O}_{4}: \mathrm{C}, 55.28 ; \mathrm{H}, 3.37 ; \mathrm{N}, 21.42$; found: $\mathrm{C}$, 55.39; H, 3.38; N, 21.52. HR-MS $m / z$ : calcd for $\mathrm{C}_{15} \mathrm{H}_{11} \mathrm{~N}_{5} \mathrm{O}_{3}[\mathrm{M}+$ $\mathrm{Na}]^{+}: 348.0639$; found: 348.0642 .

2.7.9 4i: (trans-7,7a)-5-amino-7-(4-methoxyphenyl)-1,3dioxo-2,3,7,7a-tetrahydro-1H-pyrrolo[1,2-c]imidazole-6-carbonitrile. $\mathrm{mp}=260{ }^{\circ} \mathrm{C}$, IR $\left(\mathrm{KBr}, \mathrm{cm}^{-1}\right)=3390,3340,3258,3210$, 
2183, 1775, 1713, 1662, 1596, ${ }^{1} \mathrm{H}$ NMR (400 MHz, DMSO-d 6 ): $\delta=$ 9.248 (s, NH), 7.308 (br s, $\mathrm{NH}_{2}$ ), 7.221 (d, $\left.J=8 \mathrm{~Hz}, 2 \mathrm{H}\right), 6.894$ (d, $J=8 \mathrm{~Hz}, 2 \mathrm{H}), 4.473(\mathrm{~s}, 2 \mathrm{H}), 3.739(\mathrm{~s}, 3 \mathrm{H}) \mathrm{ppm},{ }^{1} \mathrm{H}-\mathrm{NMR}(300$ MHz, DMSO- $\mathrm{d}_{6}$ with a drop of $\left.\mathrm{D}_{2} \mathrm{O}\right): \delta=7.192(\mathrm{~d}, J=8 \mathrm{~Hz}, 2 \mathrm{H})$, 6.926 (d, $J=8 \mathrm{~Hz}, 2 \mathrm{H}), 4.454$ (d, $J=7.5 \mathrm{~Hz}, 1 \mathrm{H}), 4.379$ (d, $J=$ $7.5 \mathrm{~Hz}, 1 \mathrm{H}) 3.690(\mathrm{~s}, 3 \mathrm{H})$. If DMSO was used as a solvent for ${ }^{1} \mathrm{H}$ NMR spectroscopy, a singlet peak was revealed for two adjacent protons, which implied a low amount of $\Delta \nu$ in the DMSO solvent. But in the presence of $\mathrm{D}_{2} \mathrm{O}$, two doublet peaks appeared that had $J=7.5 \mathrm{~Hz}$. It can be inferred from these results that just the trans diastereomer, confirmed by X-Ray crystallography, was the pure product; anal. calcd for $\mathrm{C}_{14} \mathrm{H}_{12} \mathrm{~N}_{4} \mathrm{O}_{3}: \mathrm{C}, 59.15, \mathrm{H}$, 4.25, N, 19.70; found: C, 59.23, H, 4.38, N, 19.41. HR-MS $m / z$ : calcd for $\mathrm{C}_{14} \mathrm{H}_{12} \mathrm{~N}_{4} \mathrm{O}_{3}[\mathrm{M}+\mathrm{Na}]^{+}$: 307.0807; found: 307.0808 .

2.7.10 4j: $\quad$ (trans-7,7a)-5-amino-1,3-dioxo-7-( $p$-tolyl)2,3,7,7a-tetrahydro-1H-pyrrolo[1,2-c]-imidazole-6-carbonitrile.

$\mathrm{mp}=275^{\circ} \mathrm{C}$; IR $\left(\mathrm{KBr}, \mathrm{cm}^{-1}\right)=3400,3318,3260,2169,1778$, 1708, 1653, 1598; ${ }^{1} \mathrm{H}$ NMR (400 MHz, DMSO-d 6 ): $\delta=8.46(\mathrm{~s}, 1 \mathrm{H}$, $\mathrm{NH}), 7.862(\mathrm{~d}, J=8 \mathrm{~Hz}, 2 \mathrm{H}), 7.438$ (d, $J=8 \mathrm{~Hz}, 2 \mathrm{H}), 7.313$ (br s, $\left.\mathrm{NH}_{2}\right), 4.448\left(\mathrm{~s}, 2 \mathrm{H}, \mathrm{CH}_{2}\right) ; 2.389(\mathrm{~s}, 3 \mathrm{H})$; anal. calcd for $\mathrm{C}_{14} \mathrm{H}_{12} \mathrm{~N}_{5} \mathrm{O}_{4}$ : C, 62.69; H, 4.50; N, 20.88; found: C, 62.73; H, 4.22; N, 20.52; HR-MS $m / z$ : calcd for $\mathrm{C}_{14} \mathrm{H}_{12} \mathrm{~N}_{5} \mathrm{O}_{4}[\mathrm{M}+\mathrm{Na}]^{+}$: 291.0858; found: 291.0859 .

2.7.11 4k: (trans-7,7a)-5-amino-1,3-dioxo-7-phenyl-2,3,7,7atetrahydro-1H-pyrrolo[1,2-c]-imidazole-6-carbonitrile. $\mathrm{mp}=$ $275^{\circ} \mathrm{C}$; IR ( $\left.\mathrm{KBr}, \mathrm{cm}^{-1}\right): 3400,3318,3260,2169,1778,1708,1653$, 1598; ${ }^{1} \mathrm{H}$ NMR (400 MHz, DMSO-d 6 ): $\delta=8.504$ (br s, NH), 7.313 (br s, $\mathrm{NH}_{2}$ ), 7.110-7.115 (m, 5H, Ar-H), 4.428 (s, 2H, $\mathrm{CH}_{2}$ ); anal. calcd for $\mathrm{C}_{13} \mathrm{H}_{10} \mathrm{~N}_{4} \mathrm{O}_{2}$ : C, 61.41, H, 3.96; N, 22.03; found: $\mathrm{C}$, 61.29; H, 3.88; N, 22.22. HR-MS $m / z$ : calcd for $\mathrm{C}_{13} \mathrm{H}_{10} \mathrm{~N}_{4} \mathrm{O}_{2}[\mathrm{M}+$ $\mathrm{Na}]^{+}: 277.0701$; found: 277.0705 .

2.7.12 41: (trans-7,7a)-5-amino-7-(3,5-dimethoxyphenyl)1,3-dioxo-2,3,7,7a-tetrahydro-1 $\mathrm{H}$-pyrrolo[1,2-c]imidazole-6-carbonitrile. $\mathrm{mp}=245^{\circ} \mathrm{C}$; IR $\left(\mathrm{KBr}, \mathrm{cm}^{-1}\right): 3402,3339,3241,3010$, 2967, 2838, 2771, 2195, 1744, 1661; ${ }^{1} \mathrm{H}$ NMR (400 MHz, DMSO$\left.\mathrm{d}_{6}\right): \delta=9.815$ (br s, NH), $8.323\left(\right.$ br s, $\left.\mathrm{NH}_{2}\right), 7.608(\mathrm{~s}, 1 \mathrm{H}), 7.591(\mathrm{~d}$, $J=8.0 \mathrm{~Hz}, 1 \mathrm{H}), 7.201(\mathrm{~d}, J=8.0 \mathrm{~Hz}, 1 \mathrm{H}), 4.636(\mathrm{~d}, J=8 \mathrm{~Hz}, 2 \mathrm{H})$, 3.889 (d, $J=8 \mathrm{~Hz}, 6 \mathrm{H})$; anal. calcd for $\mathrm{C}_{15} \mathrm{H}_{14} \mathrm{~N}_{4} \mathrm{O}_{4}: \mathrm{C}, 57.32 ; \mathrm{H}$, 4.48; N, 17.82; found: C, 57.29; H, 4.58; N, 17.79. HR-MS $m / z$ : calcd for $\mathrm{C}_{15} \mathrm{H}_{14} \mathrm{~N}_{4} \mathrm{O}_{4}[\mathrm{M}+\mathrm{Na}]^{+}$: 337.0912; found: 337.0915 .

2.7.13 4m: (trans-7,7a)-5-amino-7-(4-bromophenyl)-1,3dioxo-2,3,7,7a-tetrahydro-1H-pyrrolo[1,2-c]imidazole-6-carbonitrile. $\mathrm{mp}=271{ }^{\circ} \mathrm{C}$; IR $\left(\mathrm{KBr}, \mathrm{cm}^{-1}\right): 3391,3313,3259,3209$, 2182, 1782, 1718, 1645, 1623; ${ }^{1} \mathrm{H}$ NMR (400 MHz, DMSO-d $\left.{ }_{6}\right): \delta=$ 11.49 (s, 1H), 7.59 (d, $J=8.4 \mathrm{~Hz}, 2 \mathrm{H}), 7.39$ (br s, 2H), 7.30 (d, $J=$ $8.4 \mathrm{~Hz}, 2 \mathrm{H}) 4.57$ (d, $J=9.2 \mathrm{~Hz}, 1 \mathrm{H}) 4.54(\mathrm{~d}, J=9.2 \mathrm{~Hz}, 1 \mathrm{H}) \mathrm{ppm}$; anal. calcd for $\mathrm{C}_{13} \mathrm{H}_{9} \mathrm{BrN}_{4} \mathrm{O}_{2}$ : C, 46.85, H, 2.72; N, 16.82; found: C, 46.92; H, 2.69; N, 16.72; HR-MS $m / z$ : calcd for $\mathrm{C}_{13} \mathrm{H}_{9} \mathrm{BrN}_{4} \mathrm{O}_{2}$ $[\mathrm{M}+\mathrm{Na}]^{+}:$354.9806; found: 354.9809 .

2.7.14 4n: (trans-7,7a)-5-amino-7-(3-nitrophenyl)-1,3-dioxo2,3,7,7a-tetrahydro- $1 \mathrm{H}$-pyrrolo[1,2-c]-imidazole-6-carbonitrile. $\mathrm{mp}=265^{\circ} \mathrm{C}$; IR $\left(\mathrm{KBr}, \mathrm{cm}^{-1}\right): 3444,3347,3218,2180,1789,1751$, $1655 ;{ }^{1} \mathrm{H}$ NMR (400 MHz, DMSO-d ${ }_{6}$ ): $\delta=11.55$ (s, 1H), 8.21-7.70 $(\mathrm{m}, 4 \mathrm{H}), 7.51$ (br s, 2H), 4.79 (d, $J=8.8 \mathrm{~Hz}, 1 \mathrm{H}), 4.66$ (d, $J=$ $8.8 \mathrm{~Hz}, 1 \mathrm{H}$ ); anal. calcd for $\mathrm{C}_{13} \mathrm{H}_{9} \mathrm{~N}_{5} \mathrm{O}_{4}: \mathrm{C}, 52.16, \mathrm{H}, 3.03 ; \mathrm{N}$, 23.41; found: C, 51.92; H, 2.96; N, 23.72; HR-MS $\mathrm{m} / \mathrm{z}$ : calcd for $\mathrm{C}_{13} \mathrm{H}_{9} \mathrm{~N}_{5} \mathrm{O}_{4}[\mathrm{M}+\mathrm{Na}]^{+}$: 322.0552; found: 322.0554 .
2.7.15 4o: (trans-7,7a)-5-amino-7-(4-chlorophenyl)-1,3dioxo-2,3,7,7a-tetrahydro-1H-pyrrolo[1,2-c]imidazole-6-carbonitrile. $\mathrm{mp}=281{ }^{\circ} \mathrm{C}$; IR $\left(\mathrm{KBr}, \mathrm{cm}^{-1}\right): 3394,3318,3268,3217$, 3181, 2193, 1783, 1723, 1660, 1603; ${ }^{1} \mathrm{H}$ NMR (400 MHz, DMSO$\left.\mathrm{d}_{6}\right): \delta=7.748($ br s, NH), $7.464(\mathrm{~d}, J=8.4 \mathrm{~Hz}, 2 \mathrm{H}), 7.255$ (br s, $\mathrm{NH}_{2}$ ), 6.957 (d, $\left.J=8.4 \mathrm{~Hz}, 2 \mathrm{H}\right), 4.58(\mathrm{~s}, 2 \mathrm{H})$; anal. calcd for $\mathrm{C}_{13} \mathrm{H}_{9} \mathrm{ClN}_{4} \mathrm{O}_{2}$ : C, 54.08; H, 3.14; N, 12.28; found: C, 54.29; H, 3.21 ; N, 12.22; HR-MS $m / z$ : calcd for $\mathrm{C}_{13} \mathrm{H}_{9} \mathrm{ClN}_{4} \mathrm{O}_{2}[\mathrm{M}+\mathrm{Na}]^{+}$: 311.0311; found: 311.0313 .

2.7.16 4p: (trans-7,7a)-5-amino-7-(2,6-dichlorophenyl)-1,3dioxo-2,3,7,7a-tetrahydro-1H-pyrrolo-[1,2-c]imidazole-6-carbonitrile. $\mathrm{mp}=265{ }^{\circ} \mathrm{C}$; IR $\left(\mathrm{KBr}, \mathrm{cm}^{-1}\right):=3432,3340,3227,2182$, 1791, 1712, 1659, $1602 \mathrm{~cm}^{-1}$; ${ }^{1} \mathrm{H}$ NMR (400 MHz, DMSO-d 6 ): $\delta=$ 11.46 (br s, NH), 7.45-7.27 (m, 3H), 7.31 (br s, $\mathrm{NH}_{2}$ ), 5.13 (d, $J=$ $8.3 \mathrm{~Hz}, 1 \mathrm{H}), 4.85(\mathrm{~s}, 1 \mathrm{H})$; anal. calcd for $\mathrm{C}_{13} \mathrm{H}_{8} \mathrm{Cl}_{2} \mathrm{~N}_{4} \mathrm{O}_{2}$ : C, 48.32; $\mathrm{H}, 2.49$, N, 21.94; found: C, 48.29, H, 2.21; N, 21.81; HR-MS $m / z$ : calcd for $\mathrm{C}_{13} \mathrm{H}_{8} \mathrm{Cl}_{2} \mathrm{~N}_{4} \mathrm{O}_{2}[\mathrm{M}+\mathrm{Na}]^{+}$: 344.9922; found: 344.9925 .

\section{Experimental section}

All starting materials and solvents were purchased commercially from Merck and Sigma-Aldrich and were used as received. The ${ }^{1} \mathrm{H}$ NMR spectra were determined using Bruker Avance-400 $\mathrm{MHz}$ spectrometers with DMSO- $\mathrm{d}_{6}$ as a solvent and tetramethylsilane (TMS) as an internal standard. FT-IR measurements were carried out using a Magna 550 apparatus by using $\mathrm{KBr}$ plates. The elemental analyses (C. H. N) of the samples were recorded using a LECO CHNS 923 analyzer. The XRD patterns were evaluated using an X-ray diffractometer (PHILIPS, PW 1510 , Netherlands) with $\mathrm{Cu}-\mathrm{K} \alpha$ radiation $(\lambda=0.154056 \mathrm{~nm})$ in the range $2 \theta=0-10^{\circ}$. The TGA-DTA analyses were performed using a Bahr STA-503 instrument in air at a heating rate of $10{ }^{\circ} \mathrm{C} \mathrm{min}{ }^{-1}$. The $\mathrm{N}_{2}$ adsorption analysis was recorded at $-196{ }^{\circ} \mathrm{C}$ using an automated gas adsorption analyzer (BEL SORP mini II) and the pore diameter was calculated from the adsorption branch of the isotherm by using the $\mathrm{BJH}$ model. The FESEM analysis of the nanoparticles was carried out using a Model FE-SEM. The TEM imaging analysis was performed using a Philips EM208 transmission electron microscope with an accelerating voltage of $200 \mathrm{kV}$. The EDX analysis of the nanoparticles was carried out using a Sigma ZEISS, Oxford Instruments Field Emission. In the $\mathrm{NH}_{3}$-TPD experiments, samples were pre-treated at $573 \mathrm{~K}$ for $1 \mathrm{~h}$. After that, $\mathrm{NH}_{3}$ was adsorbed at $373 \mathrm{~K}$ for $0.5 \mathrm{~h}$. Then, physically adsorbed ammonia was removed with a pure nitrogen flow at $373 \mathrm{~K}$. XPS spectra were recorded using a ESCA System 100 spectrometer (VSW Scientific Instruments, Manchester).

\subsection{Preparation and characterization of the catalyst}

All of the steps for the functionalization of the modified surface of the mesoporous SBA-15 have been shown in Scheme 4.

\subsection{Preparation of the NNBIA ligand}

$1 \mathrm{mmol}$ of 1,2-diaminoethane was added to a mixture of $2 \mathrm{mmol}$ powdered isatoic anhydride in $5 \mathrm{~mL}$ of hot water. The reaction was stirred and refluxed for $3 \mathrm{~h}$. Then, the reaction mixture was 


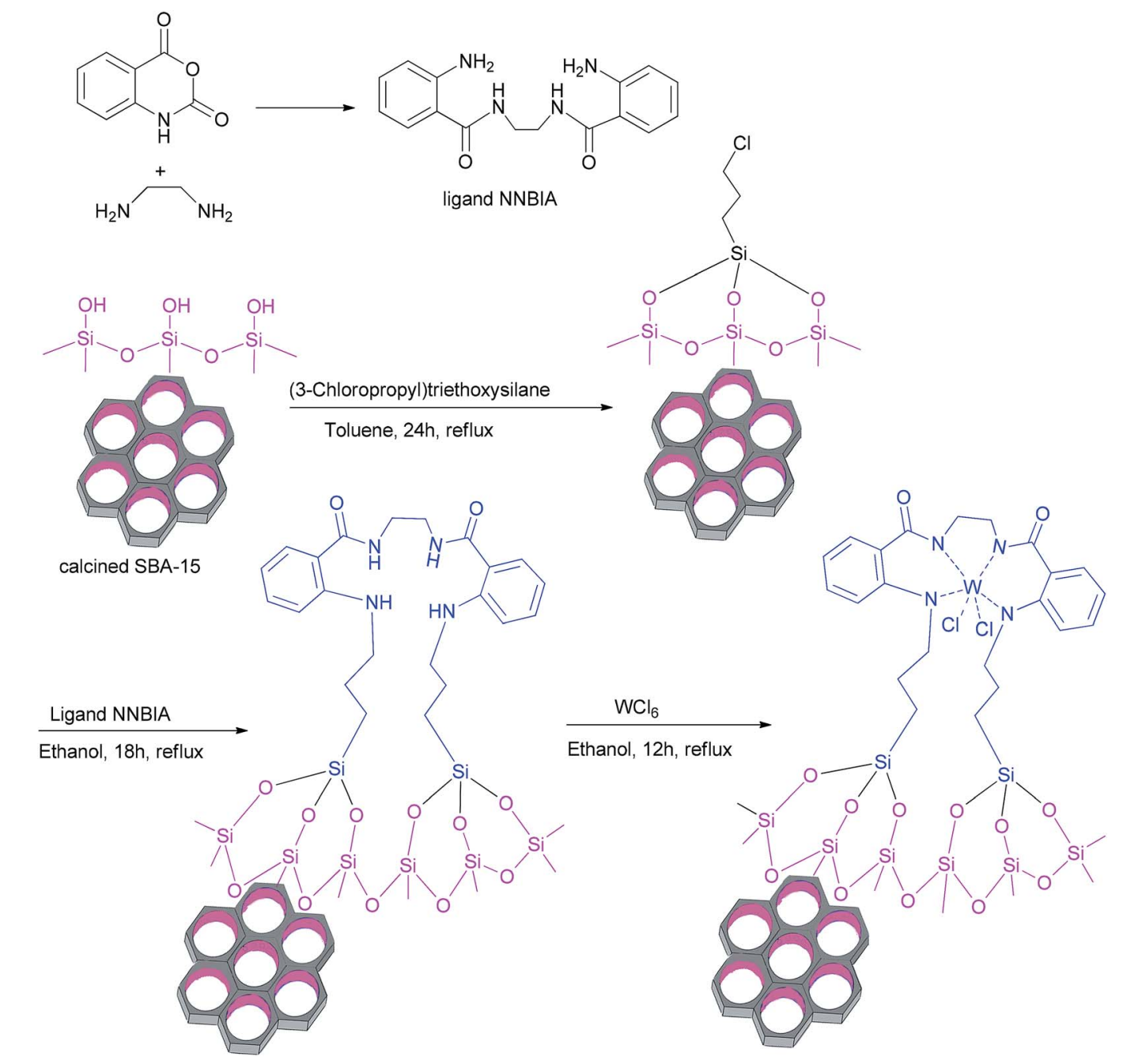

Scheme 4 The different steps for synthesis of W(IV)/NNBIA-SBA-15.

left to stand overnight to generate crystals of the product. The crystals were filtered and washed with $\mathrm{EtOH}$ and then dried to obtain the pure product. The structure of the ligand, NNBIA, was confirmed by the ${ }^{1} \mathrm{H}$ NMR that is presented in Fig. 10.

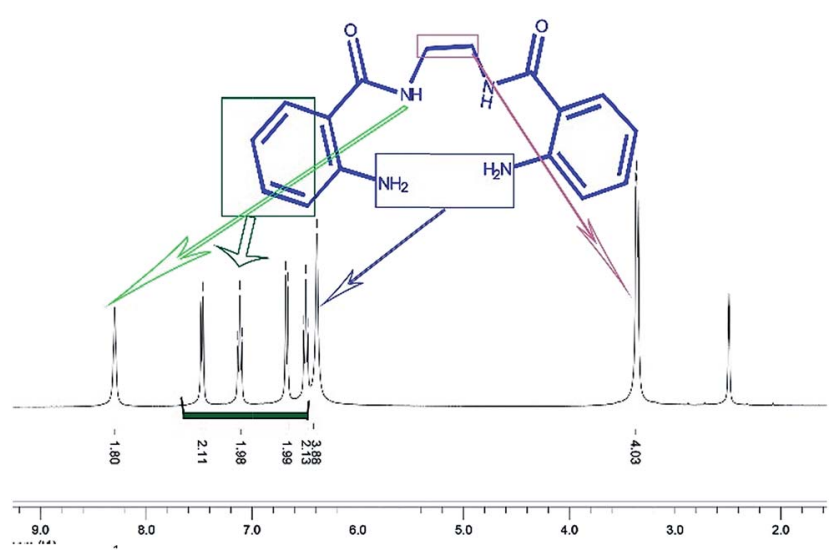

Fig. $10{ }^{1} \mathrm{H}$ NMR spectrum of the ligand, NNBIA, in DMSO- $d_{6}$.

\subsection{Preparation of SBA-15}

$4.0 \mathrm{~g}$ of pluronic 123 triblock copolymers $\left(\mathrm{EO}_{20}-\mathrm{PO}_{70}-\mathrm{EO}_{20}\right)$, as templates, were dissolved in $2.0(\mathrm{M})$ aq. $\mathrm{HCl}(120 \mathrm{~mL})$ and distilled water $(15 \mathrm{~mL})$ in a $250 \mathrm{~mL}$ round-bottom flask. The mixture was stirred at room temperature for $4 \mathrm{~h}$. Then $8.5 \mathrm{~g}$ of tetraethylorthosilicate was added dropwise to the solution. The temperature of the reaction mixture was kept at $35{ }^{\circ} \mathrm{C}$ and it was stirred for $8 \mathrm{~h}$. The synthesized gel was heated under static conditions in a Teflon-lined autoclave for $24 \mathrm{~h}$ at $100{ }^{\circ} \mathrm{C}$. A white solid precipitated and was filtered and washed with deionized water. The residual organic materials were removed by calcination at $550{ }^{\circ} \mathrm{C}$ for 8 h. ${ }^{42,48}$

\subsection{Organofunctionalization of SBA-15}

In a dry Schlenk flask, $1 \mathrm{~g}$ of SBA-15, that was activated under vacuum at $150{ }^{\circ} \mathrm{C}$ for $3 \mathrm{~h}$, was suspended in dry toluene. Then, $3 \mathrm{mmol}$ of (3-chloropropyl)triethoxysilane was added to the above suspension solution. The reaction mixture was refluxed under nitrogen for $6 \mathrm{~h}$. Finally, purification of the Cl- 
functionalized SBA-15 was achieved by Soxhlet extraction with dichloromethane for $8 \mathrm{~h}$.

\subsection{Immobilization of the NNBIA ligand over SBA-15-Cl}

The SBA-15 with chloropropyl linkers (1 g) was suspended in absolute ethanol $(60 \mathrm{~mL})$ by sonication in a $250 \mathrm{~mL}$ roundbottom flask to form a uniform dispersion. Then, $0.298 \mathrm{~g}$ (1 $\mathrm{mmol}$ ) of the NNBIA ligand was added to the solution and the reaction mixture was refluxed for $18 \mathrm{~h}$. The precipitates were washed repeatedly with toluene to remove the unreacted substrate. Then, they were put in a hot-air oven at $90{ }^{\circ} \mathrm{C}$ and were left to stand overnight to dry and furnish the functionalized SBA-15.

\subsection{Synthesis of W(Iv)/NNBIA-SBA-15}

$1 \mathrm{~g}$ of functionalized SBA-15 were suspended in $50 \mathrm{~mL}$ of absolute ethanol. Then, $0.2 \mathrm{~g}$ of $\mathrm{WCl}_{6}$ was added and the mixture was refluxed for $12 \mathrm{~h}$ to anchor the $\mathrm{W}$ (Iv). The green light solid that was $\mathrm{W}(\mathrm{Iv}) / \mathrm{NNBIA}-\mathrm{SBA}-15$, resulted. It was washed repeatedly with ethanol and dried under vacuum.

\subsection{General procedure for the preparation of the 2- azapyrrolizidine scaffold}

In a $50 \mathrm{~mL}$ round-bottom flask, $1 \mathrm{mmol}$ of isatin or aldehyde, $1 \mathrm{mmol}$ of malononitrile, and $0.03 \mathrm{~g}$ of W(Iv)/NNBIA-SBA-15 were mixed in $5 \mathrm{~mL}$ water. The mixture was stirred for $20 \mathrm{~min}$ at room temperature. Then hydantoin, as the third component, was added to the above mixture. The reaction temperature was increased to $80{ }^{\circ} \mathrm{C}$. The mixture was stirred for the appropriate time that was founded by TLC. When the reaction was over, the precipitates were collected. They were dissolved in acetone and filtered to separate the catalyst. Acetone was evaporated and the product was purified by washing $(2 \times 10 \mathrm{~mL})$ with a mixture of (3:1) ethyl acetate and hexane. The desired pure products were characterized by IR, ${ }^{1} \mathrm{H}$ NMR and C. H. N. The W(Iv)/NNBIASBA-15 could catalyze all of the reactions regardless of the substrates. The catalyst was washed three times with hot ethanol $(3 \times 10 \mathrm{~mL})$ and water $(2 \times 5 \mathrm{~mL})$, respectively.

\section{Conclusions}

A new functionalized mesoporous SBA-15 material has been introduced using a newly synthesized tetradentate ligand. The NNBIA ligand has many functional groups to increase the active site of the catalyst. The efficiency of the catalyst was evaluated by synthesizing 2-azapyrrolizidine alkaloids that have many biological properties. The one-pot reactions of isatin or aldehyde, malononitrile and hydantoin were accomplished in water as the solvent at $80{ }^{\circ} \mathrm{C}$ for the appropriate time. Some of the principles of green chemistry are followed in this synthetic method. We synthesized a wide range of 2-azapyrrolizidine alkaloids in very high yields by loading a very low amount of catalyst in the absence of any hazardous organic solvents. The benefits of this catalyst are easy reusability and high recyclability. Based on the results, the suggested method has an important role in developing the synthesis of 2-azapyrrolizidine alkaloids.

\section{Conflicts of interest}

There are no conflicts to declare.

\section{Acknowledgements}

The authors are grateful to the University of Kashan for supporting this work (grant no. 159148/73).

\section{Notes and references}

1 V. A. Chebanov, E. A. Muravyova, S. M. Desenko, V. I. Musatov, I. V. Knyazeva, S. V. Shishkina, O. V. Shishkin and C. O. Kappe, J. Comb. Chem., 2006, 8, 427. 2 B. M. Trost, Angew. Chem., Int. Ed. Engl., 1995, 34, 259.

3 W. R. J. D. Galloway, A. Bender, M. Welch and D. R. Spring, Chem. Commun., 2009, 2446.

4 M. D. Burke and S. L. Schreiber, Angew. Chem., Int. Ed. Engl, 2004, 43, 46.

5 C. R. B. Rhoden, D. G. Rivera, O. Kreye, A. K. Bauer, B. Westermann and L. A. Wessjohann, J. Comb. Chem., 2009, 11, 1078.

6 D. R. Spring, Org. Biomol. Chem., 2003, 1, 3867.

7 D. A. Horton, G. T. Bourne and M. L. Smythe, Chem. Rev., 2003, 103, 893.

8 W. R. Galloway, A. Isidro-Llobet and D. R. Spring, Nat. Commun., 2010, 1, 80.

9 K. Kumaravel and G. Vasuki, Curr. Org. Chem., 2009, 13, 1820.

10 W. R. Galloway, M. Diáz-Gavilán, A. Isidro-Llobet and D. R. Spring, Angew. Chem., Int. Ed. Engl., 2009, 48, 1194.

11 U. M. Lindström, Chem. Rev., 2002, 102, 2751.

12 J. Li, K. Kudo and S. Shiraishi, Macromol. Rapid Commun., 2000, 21, 1166.

13 E. E. Smissman, P. L. Chien and R. A. Robinson, J. Org. Chem., 1970, 35, 3818.

14 W. J. Brouillette, V. P. Jestkov, M. L. Brown, M. S. Akhtar, T. M. DeLorey and G. B. Brown, J. Med. Chem., 1994, 37, 3289.

15 L. A. Paquette, S. Brand and C. Behrens, J. Org. Chem., 1999, 64, 2010.

16 B. Rajarathinam, K. Kumaravel and G. Vasuki, ACS Comb. Sci., 2017, 19, 455.

17 S. Wang, Y. Jiang, S. Wu, G. Dong, Z. Miao, W. Zhang and C. Sheng, Org. Lett., 2016, 18, 1028.

18 N. Opačić, B. Zorc, M. Cetina, D. Mrvoš-Sermek, S. Raić-Malić and M. Mintas, Chem. Biol. Drug Des., 2005, 66, 85 .

19 Z. Liu, S. Wu, Y. Wang, R. Li, J. Wang, L. Wang, Y. Zhao and P. Gong, Eur. J. Med. Chem., 2014, 87, 782.

20 E. Vedejs and G. Martinez, J. Am. Chem. Soc., 1980, 102, 7993. 21 A. R. Chamberlin and J. Y. Chung, J. Am. Chem. Soc., 1983, 105, 3653.

22 C.-Y. Zhou, W.-Y. Yu, P. W. H. Chan and C.-M. Che, J. Org. Chem., 2004, 69, 7072. 
23 S. Karamthulla, S. Pal, M. N. Khan and L. H. Choudhury, RSC Adv., 2013, 3, 15576.

24 B. Rajarathinam and G. Vasuki, Org. Lett., 2012, 14, 5204.

25 T. Szymańska-Buzar, Coord. Chem. Rev., 2005, 249, 2195.

26 A. Koutsospyros, W. Braida, C. Christodoulatos, D. Dermatas and N. Strigul, J. Hazard. Mater., 2006, 136, 1.

27 B. Sels, D. De Vos and P. Jacobs, Angew. Chem., Int. Ed., 2005, 44, 310 .

28 R. D. Wilson, D. G. Barton, C. D. Baertsch and E. Iglesia, J. Catal., 2000, 194, 175.

29 C. D. Baertsch, K. T. Komala, Y.-H. Chua and E. Iglesia, J. Catal., 2002, 205, 44.

30 C. H. Kline and V. Kollonitsch, Ind. Eng. Chem., 1965, 57, 53.

31 X.-L. Yang, W.-L. Dai, R. Gao and K. Fan, J. Catal., 2007, 249, 278.

32 J.-C. Hu, Y.-D. Wang, L.-F. Chen, R. Richards, W.-M. Yang, Z.-C. Liu and W. Xu, Microporous Mesoporous Mater., 2006, 93, 158.

33 J. Tang, L. Wang, G. Liu, Y. Liu, Y. Hou, W. Zhang, M. Jia and W. R. Thiel, J. Mol. Catal. A: Chem., 2009, 313, 31.

34 J. E. Herrera, J. H. Kwak, J. Z. Hu, Y. Wang, C. H. Peden, J. Macht and E. Iglesia, J. Catal., 2006, 239, 200.

35 F. Somma and G. Strukul, J. Catal., 2004, 227, 344.

36 C. Martín, P. Malet, G. Solana and V. Rives, J. Phys. Chem. B, 1998, 102, 2759.

37 E. Briot, J.-Y. Piquemal, M. Vennat, J.-M. Brégeault, G. Chottard and J.-M. Manoli, J. Mater. Chem., 2000, 10, 953.

38 C. T. Kresge, M. E. Leonowicz, W. J. Roth, J. C. Vartuli and J. S. Beck, Nature, 1992, 359, 710.

39 J. S. Beck, J. C. Vartuli, W. J. Roth, M. E. Leonowicz, C. T. Kresge and K. D. Schmitt, J. Am. Chem. Soc., 1992, 114, 10834.

40 D. Zhao, J. Feng, Q. Huo, N. Melosh, G. H. Fredrickson, B. F. Chmelka and G. D. Stucky, science, 1998, 279, 548.

41 D. Zhao, Q. Huo, J. Feng, B. F. Chmelka and G. D. Stucky, J. Am. Chem. Soc., 1998, 120, 6024.

42 H. García, Pure Appl. Chem., 2003, 75, 1085.

43 L. Saikia, D. Srinivas and P. Ratnasamy, Microporous Mesoporous Mater., 2007, 104, 225.
44 A. Bordoloi, Y. Hwang, J.-S. Hwang and S. Halligudi, Catal. Commun., 2009, 10, 1398.

45 R. A. Garcia, R. van Grieken, J. Iglesias, V. Morales and N. Villajos, J. Catal., 2010, 274, 221.

46 S. Kumari, B. Malvi, A. K. Ganai, V. K. Pillai and S. Sen Gupta, J. Phys. Chem. C, 2011, 115, 17774.

47 S. Alavi, H. Hosseini-Monfared and M. Siczek, J. Mol. Catal. A: Chem., 2013, 377, 16.

48 J. S. Ghomi and A. Bakhtiari, ChemistrySelect, 2018, 3, 12704. 49 A. Taguchi and F. Schüth, Microporous Mesoporous Mater., 2005, 77, 1.

50 Q. Jiang, Z. Y. Wu, Y. M. Wang, Y. Cao, C. F. Zhou and J. H. Zhu, J. Mater. Chem., 2006, 16, 1536.

51 L. Wang, T. Qi, Y. Zhang and J. Chu, Microporous Mesoporous Mater., 2006, 91, 156.

52 N. T. S. Phan, C. S. Gill, J. V. Nguyen, Z. J. Zhang and C. W. Jones, Angew. Chem., Int. Ed., 2006, 45, 2209.

53 P. R. D. Srinivas, Microporous Mesoporous Mater., 2007, 105, 170.

54 B. Helms, S. J. Guillaudeu, M. M. Y. Xie, C. J. Hawker and E. J. M. Fréchet, Angew. Chem., Int. Ed., 2005, 44, 6384.

55 R. Kadyrov, D. Wolf, C. Azap and D. J. Ostgard, Top. Catal., 2010, 53, 1066.

56 A. J. Crisci, M. H. Tucker, M.-Y. Lee, S. G. Jang, J. A. Dumesic and S. L. Scott, ACS Catal., 2011, 1, 719.

57 N. A. Brunelli, K. Venkatasubbaiah and C. W. Jones, Chem. Mater., 2012, 24, 2433.

58 Y. H. J. Gu, S. P. Elangovan, W. Z. Y. Li, I. Toshio, Y. Yamazaki and J. Shi, J. Phys. Chem. C, 2011, 115, 21211.

59 T. D. Manning and I. P. Parkin, J. Mater. Chem., 2004, 14, 2554.

60 C. Hess, G. Tzolova-Müller and R. Herbert, J. Phys. Chem. C, 2007, 111, 9471.

61 N. Graf, E. Yegen, T. Gross, A. Lippitz, W. Weigel, S. Krakert, A. Terfort and W. E. Unger, Surf. Sci., 2009, 603, 2849.

62 J. Juan-Alcañiz, E. V. Ramos-Fernandez, U. Lafont, J. Gascon and F. Kapteijn, J. Catal., 2010, 269, 229.

63 V. Annamalai, E. F. DiMauro, P. J. Carroll and M. C. Kozlowski, J. Org. Chem., 2003, 68, 1973.

64 R. N. Butler and A. G. Coyne, Chem. Rev., 2010, 110, 6302. 